\title{
Article \\ Pathogenic Effects of Mineralocorticoid Pathway Activation in Retinal Pigment Epithelium
}

\author{
Jérémie Canonica ${ }^{1,2}{ }^{2}$ Min Zhao ${ }^{1}$, Tatiana Favez ${ }^{2}$, Emmanuelle Gelizé ${ }^{1}$, Laurent Jonet ${ }^{1}$, Laura Kowalczuk ${ }^{2}$, \\ Justine Guegan ${ }^{3}$, Damien Le Menuet ${ }^{4}$, Say Viengchareun ${ }^{4} \oplus$, Marc Lombès ${ }^{4}$, Eric Pussard ${ }^{4,5}$, Yvan Arsenijevic ${ }^{2}$ \\ and Francine Behar-Cohen $1,6, * \mathbb{D}$
}

check for updates

Citation: Canonica, J.; Zhao, M.;

Favez, T.; Gelizé, E.; Jonet, L.;

Kowalczuk, L.; Guegan, J.; Le Menuet,

D.; Viengchareun, S.; Lombès, M.;

et al. Pathogenic Effects of

Mineralocorticoid Pathway

Activation in Retinal Pigment

Epithelium. Int. J. Mol. Sci. 2021, 22,

9618. https://doi.org/10.3390/

ijms22179618

Academic Editors: James Fielding

Hejtmancik, George P. Chrousos and

Nicolas C. Nicolaides

Received: 28 July 2021

Accepted: 30 August 2021

Published: 5 September 2021

Publisher's Note: MDPI stays neutral with regard to jurisdictional claims in published maps and institutional affiliations.

Copyright: (c) 2021 by the authors. Licensee MDPI, Basel, Switzerland. This article is an open access article distributed under the terms and conditions of the Creative Commons Attribution (CC BY) license (https:/ / creativecommons.org/licenses/by/ $4.0 /)$.
1 Centre de Recherche des Cordeliers, Sorbonne Université, Université de Paris, Inserm, From Physiopathology of Retinal Diseases to Clinical Advances, 15 rue de l'Ecole de Médecine, 75006 Paris, France; jerem.canonica@gmail.com (J.C.); min.zhao@inserm.fr (M.Z.); emmanuelle.gelize@gmail.com (E.G.); laurent.jonet@crc.jussieu.fr (L.J.)

2 Department of Ophthalmology, Jules Gonin Eye Hospital, Fondation Asile des Aveugles, University of Lausanne, 1004 Lausanne, Switzerland; tatiana.favez@epfl.ch (T.F.); laura.kowalczuk@epfl.ch (L.K.); Yvan.Arsenijevic@fa2.ch (Y.A.)

3 Institut du Cerveau, ICM, iCONICS, Hôpital de la Pitié-Salpêtrière, 75013 Paris, France; justine.guegan@icm-institute.org

4 Physiologie et Physiopathologie Endocriniennes, Université Paris-Saclay, Inserm, 94276 Le Kremlin-Bicêtre, France; damien.le-menuet@u-psud.fr (D.L.M.); say.viengchareun@universite-paris-saclay.fr (S.V.); marc.lombes@universite-paris-saclay.fr (M.L.); eric.pussard@aphp.fr (E.P.)

5 Assistance Publique-Hôpitaux de Paris, Hôpital Bicêtre, Service de Génétique Moléculaire et d'Hormonologie, 94276 Le Kremlin Bicêtre, France

6 Assistance Publique-Hôpitaux de Paris, Hôpital Cochin Ophthalmopole, 75014 Paris, France

* Correspondence: Francine.behar@gmail.com

Abstract: Glucocorticoids are amongst the most used drugs to treat retinal diseases of various origins. Yet, the transcriptional regulations induced by glucocorticoid receptor (GR) and mineralocorticoid receptor (MR) activation in retinal pigment epithelium cells (RPE) that form the outer blood-retina barrier are unknown. Levels of endogenous corticoids, ligands for MR and GR, were measured in human ocular media. Human RPE cells derived from induced pluripotent stem cells (iRPE) were used to analyze the pan-transcriptional regulations induced by aldosterone-an MR-specific agonist, or cortisol or cortisol + RU486-a GR antagonist. The retinal phenotype of transgenic mice that overexpress the human MR (P1.hMR) was analyzed. In the human eye, the main ligand for GR and MR is cortisol. The iRPE cells express functional GR and MR. The subset of genes regulated by aldosterone and by cortisol + RU-486, and not by cortisol alone, mimics an imbalance toward MR activation. They are involved in extracellular matrix remodeling (CNN1, MGP, AMTN), epithelial-mesenchymal transition, RPE cell proliferation and migration (ITGB3, PLAUR and FOSL1) and immune balance (TNFSF18 and PTX3). The P1.hMR mice showed choroidal vasodilation, focal alteration of the RPE/choroid interface and migration of RPE cells together with RPE barrier function alteration, similar to human retinal diseases within the pachychoroid spectrum. RPE is a corticosteroid-sensitive epithelium. MR pathway activation in the RPE regulates genes involved in barrier function, extracellular matrix, neural regulation and epithelial differentiation, which could contribute to retinal pathology.

Keywords: retina; eye; corticoids; retinal pigment epithelium; mineralocorticoid; transcriptional regulation

\section{Introduction}

Retinal diseases are the most frequent causes of blindness in developed countries [1], and one of the major causes of vision loss is macular edema [2] that complicates retinal 
barriers' breakdown. Blood-retina barriers are formed in the inner retina by endothelial cells of retinal vessels and in the outer retina by the retinal pigment epithelium (RPE) [2]. The RPE is a highly polarized monolayer of tight-junction cells that, besides its barrier function, ensures retinoid metabolism, photoreceptor outer segment phagocytosis, immune surveillance and ion and water transports, required for retinal homeostasis [2-4].

Intraocular glucocorticoids (GCs) reduce macular edema of various origins [5,6], but exogenous and even endogenous corticoids may induce paradoxical pro-edematous effects in pachychoroid-spectrum diseases including central serous chorioretinopathy (CSCR) [7], witnessing the complexity of their action on the retina. The role of corticoids in retinal homeostasis and in diseases remains incompletely understood and underestimated. In the rat retina, neurosteroids produced by steroidogenesis in rat retinal ganglion cells [8] protected retinal neurons against ischemia through binding to the sigma-1 receptor [9], which regulates calcium, ion channels and oxidative stress [10]. In a human RPE cell line (ARPE-19), 17 $\beta$-estradiol and dehydroepiandrosterone-sulfate protected against oxidativestress-induced DNA damages [11], demonstrating the crucial role of neurosteroids in retina and RPE maintenance. In the same RPE cell line, key enzymes participating in steroid synthesis were identified and transformation of progesterone into cortisol was found in culture media, suggesting that an equivalent of hypothalamic-pituitary-adrenal axis in adult retinal pigment epithelium may exist [12]. GCs act through binding to the glucocorticoid (GR) and the mineralocorticoid receptor (MR), both expressed in various cells in the retina in rodents and in humans, including the RPE [13-16]. Evidence from animal and cellular models converges to indicate that in the retina, as in other non-classical MR-sensitive tissues, MR pathway overactivation is pathogenic [15-21] and causes pathogenic features similar to CSCR, a disease that develops due to focal disruption of the RPE barrier function [19]. Indeed, GCs were shown to regulate the RPE functions [22-24] and aldosterone to cause RPE/choroid pathology in vivo [21]. However, the transcriptional regulations induced specifically in the RPE by MR and/or GR activation are unknown.

The aim of this study was to analyze the pan-transcriptional regulations induced in human induced pluripotent stem cell (hiPSC)-derived RPE (iRPE) cells by corticoids with specific inhibitors of their receptors to decipher specific genes regulated by MR or GR activation. P1.hMR transgenic mice that express the human MR were further used to analyze the consequence of MR overactivation on the retina.

\section{Results}

2.1. RPE Cells Differentiated from hiPSC Express RPE Characteristic Marker Genes and Exhibit High Transepithelial Resistance

We used a modified protocol described by Singh, R. and colleagues [25] to differentiate and expand in 60 days hiPSC into pure iRPE cells [26] (Figure 1a) that display many features of a native RPE [27]. Experiments were performed on serially expanded P3 iRPE cells at day 42.

The iRPE cells cultured on a transwell grew in monolayers of polygonal pigmented cells (Figure $1 \mathrm{~b}, \mathrm{c}$ ) and formed a functional barrier as shown by occludin and ZO-1 immunostaining (Figure 1d) and by a high transepithelial resistance (TER) $\left(306.60 \pm 81.49 \Omega \mathrm{cm}^{2}\right)$ [25] (Figure 1e). Most of RPE characteristic marker genes involved in the visual cycle, phagocytosis, pigment synthesis and ion channel transport were expressed in iRPE cells, human fetal RPE (hfRPE) cells and in post-mortem human RPE (phRPE) controls (Figure 1f,g). Expression of RPE65, RLBP1, MERTK and BEST1 was also demonstrated at the protein level by immunolocalization in iRPE (Figure 1h). These results indicate that P3 iRPE cells possessed morphological and functional characteristics and gene and protein expression profiles similar to human RPE. 
a

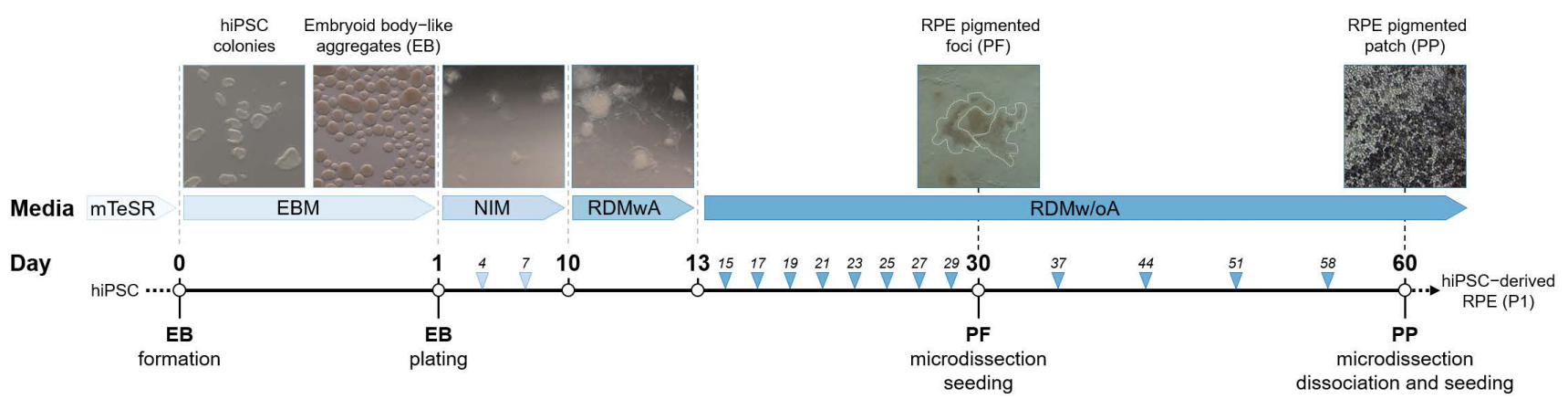

b
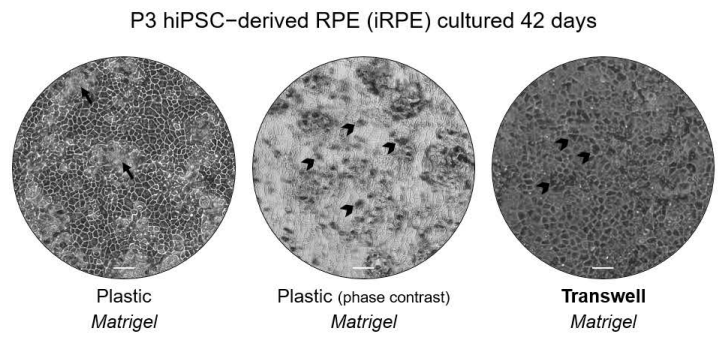

C
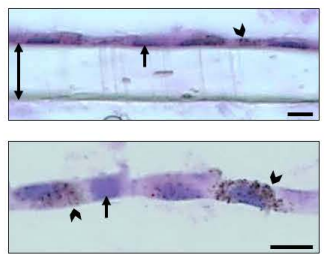

d
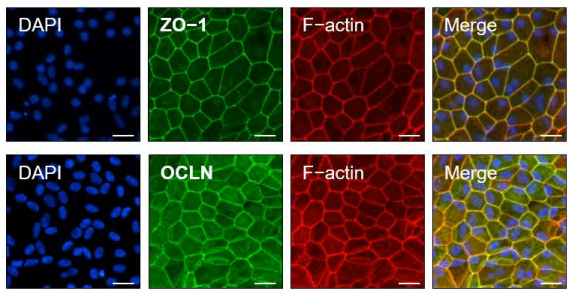

e

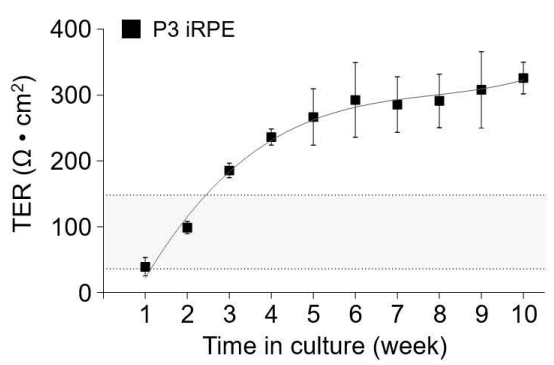

Time in culture (week) f

bp $\quad \frac{\mathrm{hiPSC}}{+\mathrm{RT}-\mathrm{RT}}\left|\frac{\mathrm{hfRPE}}{+\mathrm{RT}-\mathrm{RT}}\right| \frac{\mathrm{phRPE}}{+\mathrm{RT}-\mathrm{RT}} \mid \frac{\mathrm{iRPE}}{+\mathrm{RT}-\mathrm{RT}} \quad \begin{array}{r}P C R \\ \text { Product }\end{array}$

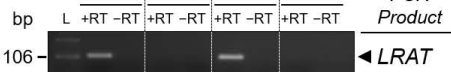
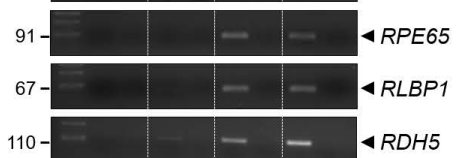

$121-$
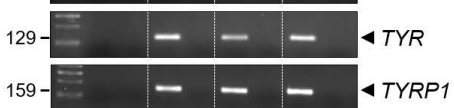

$199-\equiv-\quad-\quad-\quad-\quad \triangle P M E L$

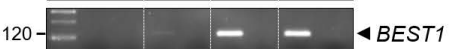

$109-\equiv-\quad-\quad-\quad-\quad 4 G A P D H$ g

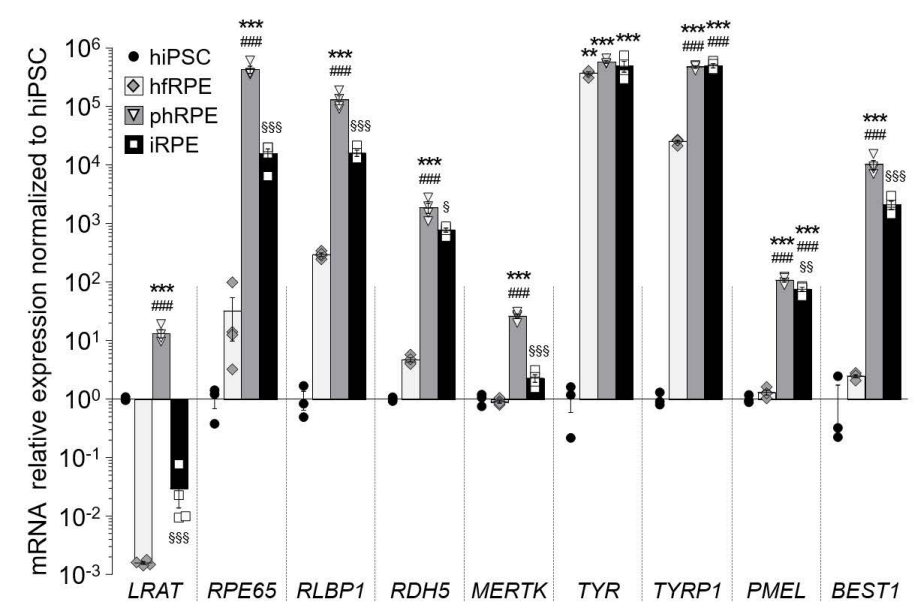

h

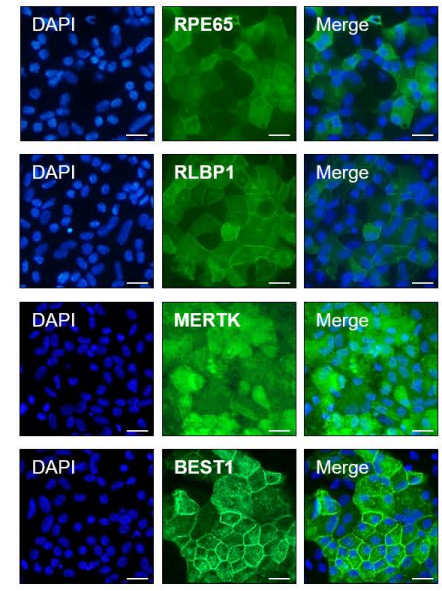

Figure 1. Human induced pluripotent stem cell (hiPSC)-derived RPE cells (iRPE) express RPE characteristic marker genes and exhibit transepithelial resistance. (a) Protocol used to expand and differentiate hiPSC into human iRPE cells in 60 days. RPE pigmented foci are marked by white dashed lines. (b) Monolayer of pigmented iRPE cells at passage 3 (arrowhead). When grown on plastic, iRPE cells form dome-like cellular structures across cell culture (arrow). (c) Transversal sections of pigmented iRPE cells cultured on transwell (double arrow). Pigment granules (arrowhead). Scale 
bar: $20 \mu \mathrm{m}$. (d) Immunofluorescence of endogenous TJP1 (encoding ZO-1), OCLN and F-actin proteins in iRPE cells. Scale bar $=30 \mu \mathrm{m}$. (e) Weekly measurements of transepithelial resistance (TER) in iRPE cells cultured. TER is measured with an EVOM2 epithelial voltohmmeter and calculated as net $\Omega \mathrm{cm}^{2}$. Gray zone between the two dashed lines corresponds to proposed functional TER values measured in native human adult RPE monolayers. Values are means \pm SEM, $n=5-12$ per time-point measurements. (f) Analysis by qualitative RT-PCR of the expression profile of specific RPE genes involved in the visual cycle (LRAT, RPE65, RLBP1 and RDH5), phagocytosis (MERTK), pigment synthesis (TYR, TYRP1 and PMEL) and ion channel transport (BEST1). The housekeeping gene GAPDH served as a control for RNA integrity. (g) Quantification by RT-qPCR of specific RPE marker mRNA transcript expression relative to GAPDH in hfRPE $(n=4)$, phRPE $(n=4)$ and iRPE $(n=4)$ normalized to undifferentiated hiPSC $(n=3)$. Data are represented in a $\log _{10}$ scale. Values are means \pm SEM. ${ }^{* *} p<0.01,{ }^{* * *} p<0.001$, hfRPE, phRPE and iRPE versus hiPSC, \#\#\# $p<0.001$, phRPE and iRPE versus hfRPE, ${ }^{\S} p<0.05$, $\S \S p<0.01, \S \S \S p<0.001$, iRPE versus phRPE. (h) Representative analysis by immunofluorescence of endogenous RPE65, RLBP1, MERTK and BEST1 protein expression in iRPE cells. RPE65, RLBP1, MERTK and BEST1 staining is in green, and DAPI staining is in blue. Scale bar $=30 \mu \mathrm{m}$. mTeSR, feeder-free maintenance medium for human ES and iPS cells; EBM, embryoid-body-like aggregate media; NIM, neural induction media; RDMwA, RPE differentiation media with vitamin A; RDMw /oA, RPE differentiation media without vitamin A; P, passage; ZO-1, zonula occludens-1; OCLN, occluding; DAPI, 4',6-diamidino-2-phenylindole; hfRPE, human fetal RPE; phRPE, post-mortem human RPE tissue; bp, base pair; L, ladder; +RT, presence of reverse transcriptase; $-\mathrm{RT}$, absence of reverse transcriptase; LRAT, lecithin retinol acyltransferase; RPE65, retinoid isomerohydrolase; RLBP1, retinaldehyde-binding protein 1; RDH5, retinol dehydrogenase 5; MERTK, MER proto-oncogene tyrosine kinase; TYR, tyrosinase; TYRP1, tyrosinase-related protein 1; PMEL, premelanosome protein; BEST1, bestrophin 1; GAPDH, glyceraldehyde-3-phosphate dehydrogenase.

2.2. Mineralocorticoid and Glucocorticoid Receptors Are Stably Expressed and Are Functional in iRPE Cells

No trace of any exogenous corticosteroids was detected in the cell culture media added to iRPE (Supplementary Table S1), and the human RPE did not synthesize or secrete glucocorticoid or mineralocorticoid hormones, contrarily to what was previously reported [12]. In addition, while expression of HSD11B1 was detected in a fresh phRPE, it was not detected in either hfRPE or in iRPE cells (Figure 2a,b). HSD11B2 could not be detected in either human RPE samples tested or in iRPE cells, suggesting that in our cellular model, cortisol added in the culture media would not be metabolized into inactive forms.

Physiologic corticoid levels were measured in the aqueous humor of patients operated for cataract surgery ( 8 males, $68 \pm 8.7$ years old, without any retinal or systemic pathology) and in the vitreous of patients operated for epiretinal membrane (12 males, $64 \pm 5$ years old, without any other retinal or systemic pathology). The mean cortisol (F) concentration was $3.2 \pm 1.4 \mathrm{ng} / \mathrm{mL}$ in aqueous humor and $2.94 \pm 1.2 \mathrm{ng} / \mathrm{mL}$ in the vitreous fluid; the mean cortisone $(\mathrm{E})$ concentration was $0.7 \pm 0.4 \mathrm{ng} / \mathrm{mL}$ in aqueous humor and $1.23 \pm 0.6 \mathrm{ng} / \mathrm{mL}$ in the vitreous; and the $\mathrm{E} / \mathrm{F}$ ratio was significantly higher in the vitreous than in the aqueous humor $(0.21 \pm 0.09$ versus $0.42 \pm 0.11, p<0.0001)$ (Figure $2 c-e)$, indicating that $11 \beta H S D 2$ enzyme activity is higher in the posterior segment of the human eye. The mineralocorticoid hormones aldosterone, 11-deoxycorticosterone and 18-hydroxycorticosterone were not measurable in iRPE cells, human RPE/choroid explant culture media or in human aqueous and vitreous humors, indicating that in physiological conditions cortisol is the main natural ligand of MR in the retina. 
a

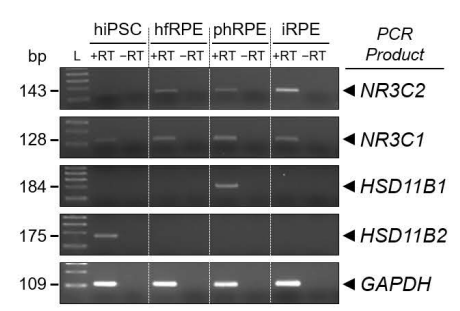

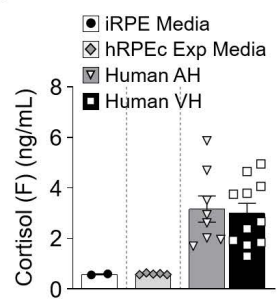

d

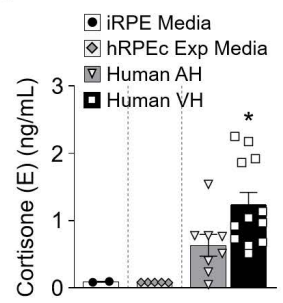

e

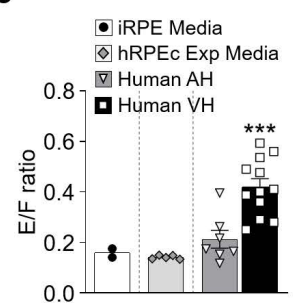

b

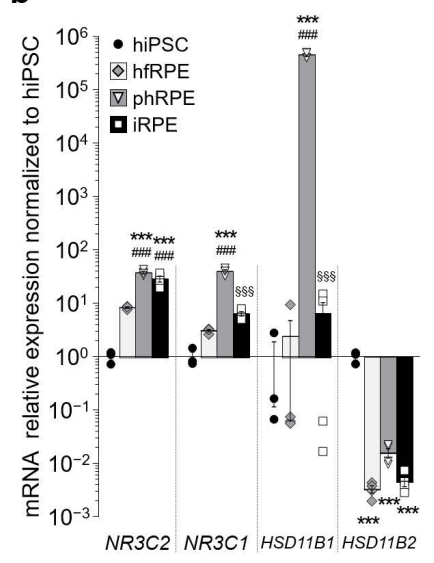

f

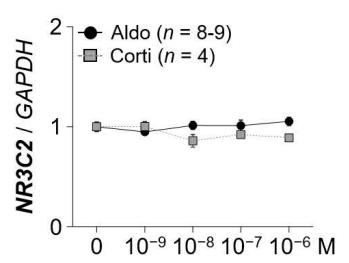

g

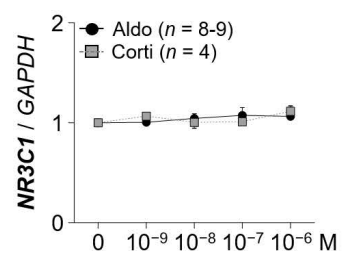

Figure 2. Mineralocorticoid and glucocorticoid receptors are expressed in iRPE cells. (a) Analysis by qualitative RT-PCR of the mineralocorticoid receptor (MR) encoded by NR3C2 and the glucocorticoid receptor (GR) encoded by NR3C1, HSD11B1 and HSD11B2 mRNA expression in iRPE cells. The housekeeping gene GAPDH served as a control for RNA integrity. (b) Quantification by RT-qPCR of expression of NR3C2, NR3C1, HSD11B1 and HSD11B2 relative to GAPDH in hfRPE $(n=4)$, phRPE $(n=4)$ and iRPE $(n=4)$ normalized to undifferentiated hiPSC $(n=3)$. Data are represented in a $\log _{10}$ Scale. Values are means \pm SEM. ${ }^{* * *} p<0.001$, hfRPE, phRPE and iRPE versus hiPSC, ${ }^{* \#} p<0.001$, phRPE and iRPE versus hfRPE, $\S \S \S p<0.001$, iRPE versus phRPE. (c-e) Cortisol (c) and cortisone (d) levels and cortisone/cortisol ratio (e) measured in iRPE apical cell culture media $(n=2)$, human RPE/choroid explant cell culture media $(n=5)$, human aqueous humor $(\mathrm{AH})(n=8)$ and human vitreous humor $(\mathrm{VH})(n=12)$. Values are means \pm SEM. Unpaired $t$-test with Welch's correction. ${ }^{* *} p<0.01$, ${ }^{* * *} p<0.001$, Human VH versus Human AH. (f) and (g) Dose-dependency expression of NR3C2 (f) and NR3C1 (g) relative to GAPDH following aldosterone or cortisol treatment $\left(10^{-9}-10^{-6} \mathrm{M}\right)$ in iRPE cells. Untreated cells' mRNA expression was arbitrarily set to 1 . Values are means \pm SEM.

Similar NR3C2 (encodes MR) and NR3C1 (encodes GR) expression was found in iRPE cell, hfRPE and phRPE control samples (Figure 2a,b). NR3C2 (Figure 2f) and NR3C1 (Figure 2g) expression was not modified by various concentrations of aldosterone or cortisol, demonstrating that iRPE stably express MR and GR. Both aldosterone and cortisol induced the translocation of MR (Figure 3a,b) and GR (Figure 3d,e) from the cytoplasm to the nucleus, as shown by immunofluorescence staining and Western blot of proteins obtained from cytoplasmic and nuclear fractions. When compared to unliganded MR, both aldosterone and cortisol increased the apparent molecular weight of MR detected on Western blots (Figure 3b), suggesting receptor phosphorylation [28,29]. Mouse cortical collecting duct (mCCD) cells with known functional endogenous MR expression served as MR positive control [30] (Figure 3b). In addition, both aldosterone (Figure 3c) and cortisol (Figure 3f) up-regulated the expression of known corticosteroid target genes, such as FKBP prolyl isomerase 5 (FKBP5), glucocorticoid-induced leucine zipper protein (GILZ), period circadian regulator 1 (PER1), sodium channel epithelial 1 alpha subunit (SCNN1A) and serum/glucocorticoid-regulated kinase 1 (SGK1). Gene expression of neutrophil gelatinase-associated lipocalin (NGAL encoded by LCN2), a mineralocorticoid target in the cardiovascular system [31], was up-regulated only following cortisol treatment (Figure 3f). These results show that the RPE is a non-classical mineralocorticoid epithelial cell layer deprived of the cortisol-inactivating enzyme $11 \beta \mathrm{HSD} 2$. 
a

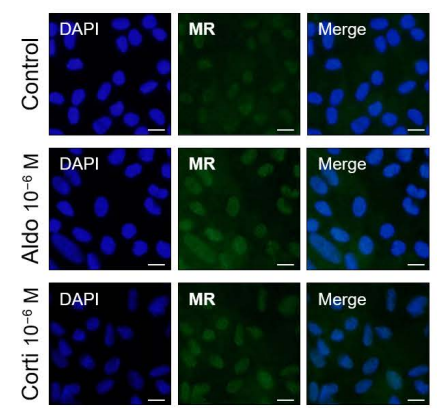

d

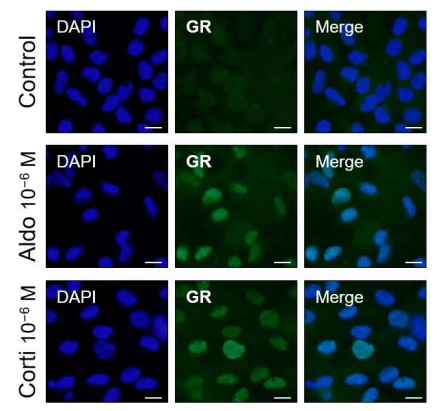

b

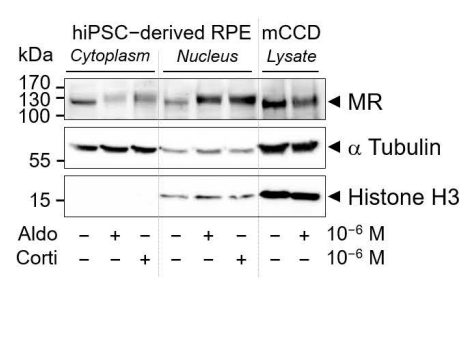

C

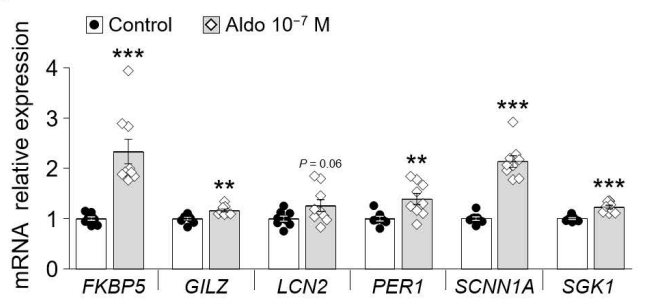

e

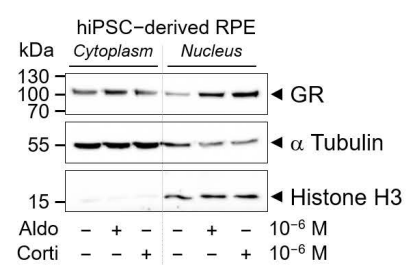

f

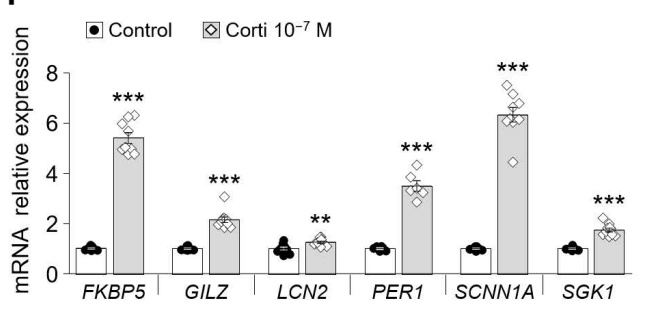

Figure 3. GR and MR are functional in hiPSC-derived RPE cells (iRPR). (a) and (d) Representative analysis by immunofluorescence of endogenous MR (a) and GR (b) protein expression following aldosterone (aldo) or cortisol (corti) $1 \mathrm{~h}$ treatment $\left(10^{-6} \mathrm{M}\right)$ in iRPE cells. MR and GR staining is in green, and DAPI staining is in blue. Scale bar: $5 \mu \mathrm{m}$. (b) and (e) Analysis by Western blot of endogenous MR (b) and GR (e) protein expression following aldosterone or cortisol $1 \mathrm{~h}$ treatment $\left(10^{-6} \mathrm{M}\right)$ in iRPE cells cytoplasmic or nuclear fractions. As a positive control for MR protein expression, mouse cortical collecting duct cells (mCCD) with known functional MR expression were treated for $1 \mathrm{~h}$ with $50 \mathrm{nM}$ aldosterone. $\alpha$-Tubulin and Histone $\mathrm{H} 3$ were used as loading controls for the cytoplasmic and nuclear fractions, respectively. Arrows indicate the expected size of the 107 kDa MR, 94 kDa GR, 50 kDa $\alpha$-Tubulin and 15 kDa Histone H3 proteins. (c) and (f) Analysis by RT-qPCR in iRPE cells following aldosterone (c) or cortisol (f) $24 \mathrm{~h}$ treatment $\left(10^{-7} \mathrm{M}\right)$ of the expression profile of genes (FKBP5, GILZ, LCN2, PER1, $S C N N 1 A, S G K 1)$ known to be up-regulated by corticosteroids. mRNA transcript expression was relative to the expression of the housekeeping gene GAPDH. $n=6-9$ per experimental condition. Values are means \pm SEM. ${ }^{* *} p<0.01,{ }^{* * *} p<0.001$.

\subsection{RNA-Seq Transcriptome Analysis Identified Corticosteroid-Regulated Genes in iRPE Cells}

RNA-Seq data analysis identified 90 up- and 122 down-regulated candidate target genes for MR activation in aldosterone-treated iRPE cells when compared to untreated cells (Figure 4a,b and Supplementary Tables S2 and S3). Comparative analysis between transcriptome profiles of cortisol-treated iRPE cells and untreated cells predicted 99 upand 41 down-regulated genes to be differentially expressed by cortisol (Figure 4c,d and Supplementary Tables S4 and S5). Cortisol and RU-486 co-treatment in iRPE cells resulted in 123 up- and 137 down-regulated genes compared to untreated cells (Figure 4e,f and Supplementary Tables S6 and S7). Several genes were regulated by corticosteroids in a similar manner in all three experimental treatments. Indeed, $\mathrm{C}-\mathrm{X}-\mathrm{C}$ motif chemokine receptor 4 (CXCR4), dual-specificity phosphatase 6 (DUSP6), EPH receptor A8 (EPHA8), inhibitory synaptic factor family member 2B (FAM196B), FKBP5, hydrogen voltage-gated channel 1 (HVCN1), PER1, prostaglandin E receptor 2 (PTGER2), S100 calcium-binding protein A2 (S100A2), SCNN1A, serpin family A member 3 (SERPINA3) and transmembrane protein 72 (TMEM72) expression was increased in iRPE cells treated with either aldosterone, cortisol or cortisol + RU-486 (Figure $4 \mathrm{~g}, \mathrm{~h}$ ). Common down-regulated genes were calponin 1 (CNN1), gap junction protein delta-2 (GJD2), oligodendrocyte myelin glycoprotein (OMG) and somatostatin (SST1) (Figure 4g,i). 
a

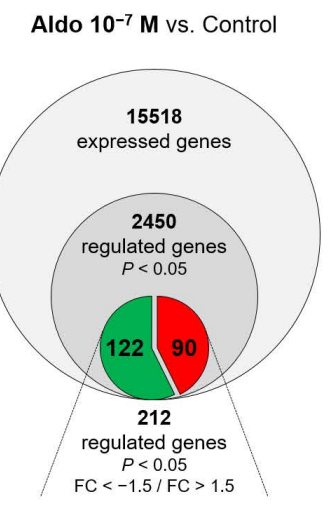

C

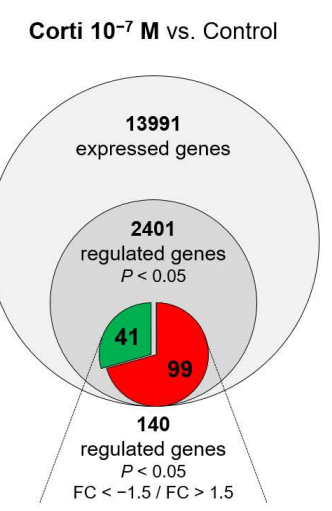

Corti $10^{-7} \mathrm{M}+\mathrm{RU}-48610^{-5} \mathrm{M}$ vs. Control

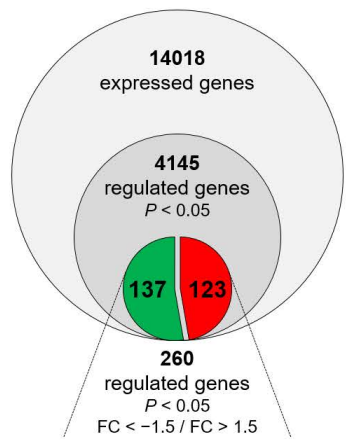

b

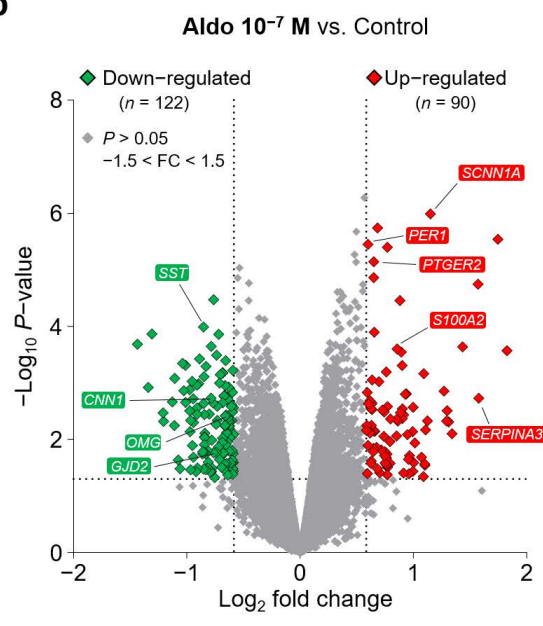

d

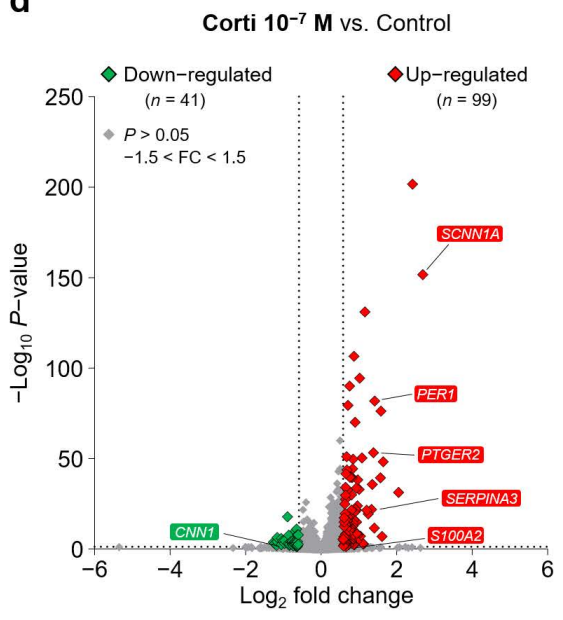

f

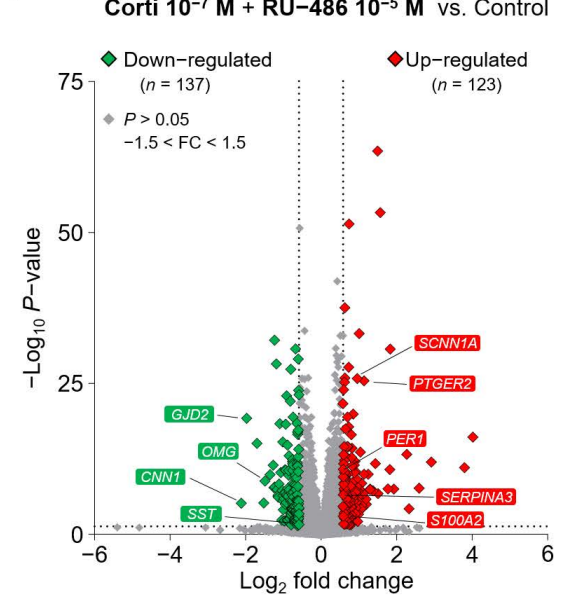

g

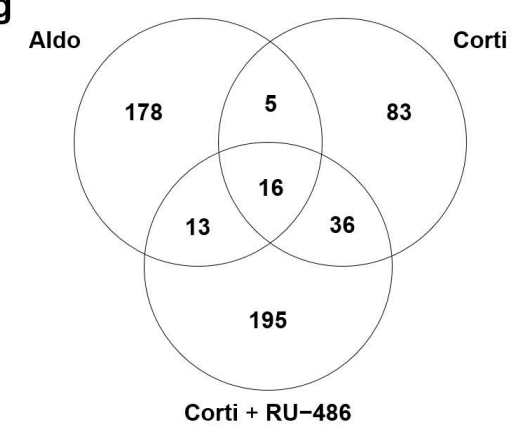

Number of DEG specific (1) or shared by 2 or 3 experimental conditions

\begin{tabular}{|c|c|c|}
\hline 16 & 54 & 456 \\
\hline 3 & 2 & 1
\end{tabular}

h

\begin{tabular}{|c|c|c|c|c|c|}
\hline \multicolumn{3}{|c|}{$\begin{array}{l}\text { Up-regulated } \\
\text { genes }\end{array}$} & \multicolumn{3}{|c|}{$\begin{array}{c}\text { Down-regulated } \\
\text { genes }\end{array}$} \\
\hline$A B C A 4$ & -1 & 1691.54 & AMTN & --2 & $-208-2.37$ \\
\hline$A B C C 3$ & 1.55 & -2.80 & ANKRD1 & & $-1.79-1.85$ \\
\hline$A D H 1 B$ & 1.743 & $306-$ & C1orf61 & $-{ }^{-1}$ & $-1.95-1.63$ \\
\hline$A G X T$ & 2.13 & -502 & $C D C 2 O B$ & --1 & $-1.58-1.85$ \\
\hline ATP 6 VOA4 & 1.551 & 158 & CNN1 & $-1.72-2$ & $-226-432$ \\
\hline 34GALNT1 & -1 & 1512.46 & COL1A1 & & $-1.68-1.64$ \\
\hline$B / C D L 1$ & -1 & 1.641 .55 & $D E P D C 1 B$ & $--^{-1}$ & $-1.69-1.65$ \\
\hline CHST11 & -1 & 1.551 .50 & FAM81B & -1.51 & --1.61 \\
\hline CXCR4 & 1.521 & 1811.64 & GFRA2 & -1.61 & -2.01 \\
\hline$D K K 1$ & -1 & 1762.47 & GJD2 & $-167-1$ & $-1.70-3.92$ \\
\hline$D R G X$ & 1.85 & -1.64 & IGFBP3 & $-1.70-1$ & -1.64 \\
\hline DUSP5 & -1 & 1.844 .82 & INHBA & -2 & $-2.07-1.96$ \\
\hline DUSP6 & 1.571 & 1822.85 & ITGA11 & $--^{-2}$ & $-2.24-2.19$ \\
\hline EPHA8 & 1702 & 2381.50 & KRT81 & -2 & $2.35-2.06$ \\
\hline FAM196B & 1.5419 & 1951.54 & $M G P$ & -2.16 & -2.21 \\
\hline FKBP5 & 1.905 & 5362.02 & MIR9-1 & -1 & $-1.95-1.63$ \\
\hline FOSL1 & 1.89 & -3.81 & NACAD & -1 & $-1.55-1.84$ \\
\hline HMGA1 & 1.53 & -1.97 & NDST3 & & $-1.54-1.69$ \\
\hline HVCN1 & $1 . 8 7 \longdiv { 4 }$ & 4151.97 & NTRK3 & & $-1.61-1.97$ \\
\hline IQGAP2 & -1.0 & $\begin{array}{lll}1.63 & 1.52\end{array}$ & OMG & $-1.58-2$ & $-2.02-2.80$ \\
\hline ITGB3 & 1.71 & -1.94 & SST & $-1.81-1$ & $-1.69-1.60$ \\
\hline KBTBD8 & -1. & 1.721 .67 & TGM2 & $--^{-2}$ & $-2.40-2.86$ \\
\hline KCNA5 & -1.5 & 1.571 .53 & ZNF367 & -1 & $-1.61-1.62$ \\
\hline MAFF & -15 & 1.501 .87 & & & E \\
\hline MCTP2 & 1.611 .0 & 1.62 - & & $\bar{\varangle}$ & 0 J \\
\hline METTL7A & -17 & 1.771 .91 & & & $\vec{\partial}$ \\
\hline MIR6883 & -30 & 3.001 .51 & & & + \\
\hline MIR7-1 & -2. & 2151.69 & & & Ẽ \\
\hline NDRG4 & -1.5 & 1.572 .71 & & & u \\
\hline PCP4 & -10 & 1.611 .55 & & & change \\
\hline PER1 & 1.513 .0 & 3.001 .51 & & & \\
\hline PLAUR & 2.16 & -2.38 & & & \\
\hline
\end{tabular}

PLAUR $2.16-2.38$

PLIN2 -1.602 .83$

POU5F1 2.97 3.13 -

PRLR - 2.011 .66

PTGER2 1.572621 .95

$\begin{array}{llll}P T X 3 & 1.54 & - & 2.14\end{array}$

\begin{tabular}{r|rr} 
RND2 & -1.85 & 1.51 \\
\hline PS6KA2 & -179 & 1.54
\end{tabular}

S100A2 1.811 .661 .71

SCNN1A 2.22 2.4. 2.2

$\begin{array}{llll}\text { SERPINA3 } & 2.99 & 2.53 & 1.62\end{array}$

SLC1A7 -1.601 .84$

SLC3A1 $1.87-1.72$

SOD2 -1691.52

ST3GAL5 -1721.75

TMEM72 1.114 .051 .10

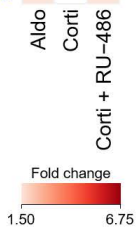

Figure 4. RNA-Seq transcriptome analysis identified corticosteroid-regulated genes in iRPE cells. (a), (c) and (e) Venn 
diagram representing total expressed genes identified by the RNA-Seq transcriptome analysis, significantly regulated genes $(p<0.05)$ and significantly corticosteroid-regulated genes as predicted by the RNA-Seq data analysis with fold change (FC) values lower than -1.5 (down-regulated genes in green) and higher than 1.5 (up-regulated genes in red) $(p<0.05 ; \mathrm{FC}<-1.5 / \mathrm{FC}>1.5)$ in iRPE cells following aldosterone (aldo) $10^{-7} \mathrm{M}$ (a), cortisol (corti) $10^{-7} \mathrm{M}$ (c) or cortisol $10^{-7} \mathrm{M}+\mathrm{RU}-48610^{-5} \mathrm{M}$ (e) $24 \mathrm{~h}$ treatment. Corticosteroid-treated iRPE cells are compared to untreated cells. (b), (d) and (f) Volcano plots highlighting differentially expressed genes (DEGs) in aldosterone- (b), cortisol- (d) or cortisol + RU-486treated (f) iRPE cells versus untreated cells. $p$-value (represented in a $-\log _{10}$ scale) and fold-change (represented in a $\log _{2}$ scale) cut-off is 0.05 (horizontal dotted line) and 1.5 (vertical dotted lines), respectively. Each up- and down-regulated expressed transcript is indicated in red and green diamonds, respectively. Representative corticosteroid-regulated DEGs of interest with comparable regulation in all three experimental treatments are shown in red (up-regulated) and green (down-regulated) rectangles. (g) Number of differentially expressed genes in corticosteroid-treated iRPE cells specific to one or shared by 2 or 3 of the following aldosterone $\left(10^{-7} \mathrm{M}\right)$, cortisol $\left(10^{-7} \mathrm{M}\right)$ and cortisol $\left(10^{-7} \mathrm{M}\right)+\mathrm{RU}-486\left(10^{-5} \mathrm{M}\right)$ experimental treatments. (h) and (i) Lists of up-regulated (h) and down-regulated (i) genes identified by RNA-Seq data analysis in iRPE cells with a comparable differential expression in 2 or 3 experimental conditions. Fold-change values for each gene and specific to each experimental treatment are indicated in the tables. Genes regulated by corticosteroids in a similar manner in all three experimental treatments are in bold type. Genes regulated in a similar manner in the aldosterone $10^{-7} \mathrm{M}$ and cortisol $10^{-7} \mathrm{M}+\mathrm{RU}-48610^{-5} \mathrm{M}$ experimental conditions in which aldosterone and cortisol agonists should mostly bind to and activate MR are in blue. SST, somatostatin; CNN1, calponin 1; OMG, oligodendrocyte myelin glycoprotein; GJD2, gap junction protein delta-2; SCNN1A, sodium channel epithelial 1 alpha subunit; PER1, period circadian clock 1; PTGER2, prostaglandin E receptor 2; S100A2, S100 calcium-binding protein A2; SERPINA3, serpin family A member 3.

Interestingly, expression of some genes (10 up-regulated genes and 3 down-regulated genes) was comparable in the aldosterone and cortisol + RU-486 experimental conditions, representing genes resulting mostly from MR pathway activation (Figure 4g-i).

\subsection{Validation of RNA-Seq-Predicted Corticosteroid-Regulated Genes}

Some of the genes predicted by the RNA-Seq data to be differentially expressed were tested by RT-qPCR analysis for validation on samples distinct from those used for the RNASeq analyses (Figure 5 and Scheme 1). Good correlations were obtained between RNA-Seq and RT-qPCR results (Figure $5 \mathrm{a}-\mathrm{c}$ ) following aldosterone or cortisol treatment for SERPINA3 (Figure 5d,i), SCNN1A (Figure 5e,j), S100A2 (Figure 5f,k), PTGER2 (Figure 5g,l) and PER1 (Figure 5h,m). Up-regulation of these genes by the aldosterone was MR-dependent, as shown by the blocking effect of the MR antagonist spironolactone. Cortisol induced the regulation of selected genes that were both MR- and GR-dependent such as SERPINA3 (Figure 5i), SCNN1A (Figure 5j), PTGER2 (Figure 5l) and PER1 (Figure 5m). Interestingly, the potency to counteract the effect of the glucocorticoid hormone differed between the MR and the GR antagonist and was specific to the targeted genes. Indeed, up-regulation in SCNN1A and PER1 gene expression by cortisol was mostly reduced by the GR antagonist RU-486 and to a lesser extent by the MR antagonist spironolactone. On the other hand, RU-486 had a lesser effect than spironolactone to block the increased expression of SERPINA3, S100A2 and PTGER2. Furthermore, aldosterone or cortisol increased SERPINA3 (Figure 5n), SCNN1A (Figure 5o), S100A2 (Figure 5p), PTGER2 (Figure 5q) and PER1 (Figure 5r) expression in a dose-dependent manner in iRPE cells. Other genes (ABCC3, HMGA1, PLAUR and PTX3) were validated by RT-qPCR (Scheme 1). 
a

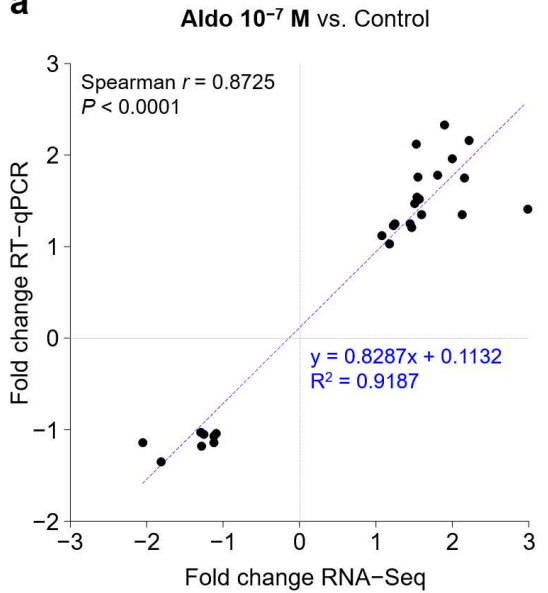

b

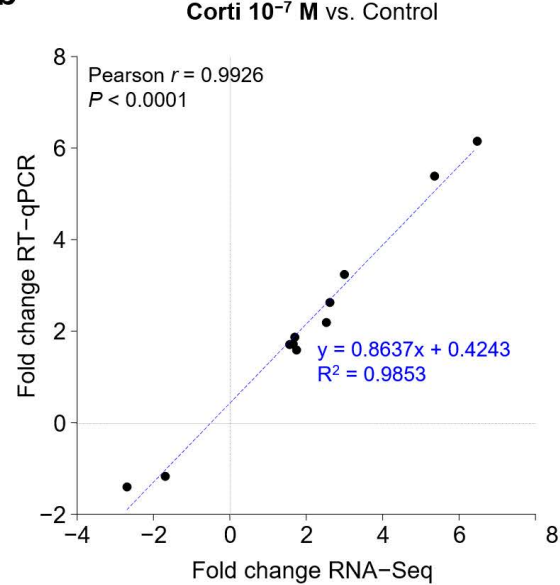

C

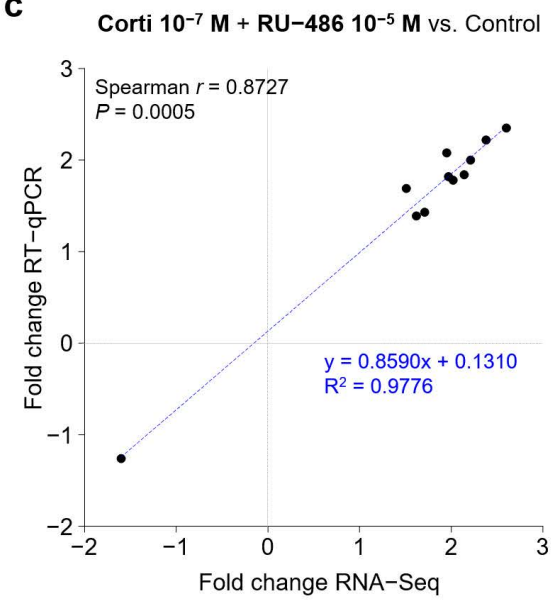

f

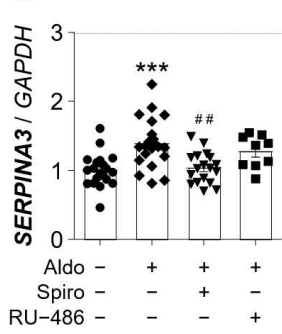

e
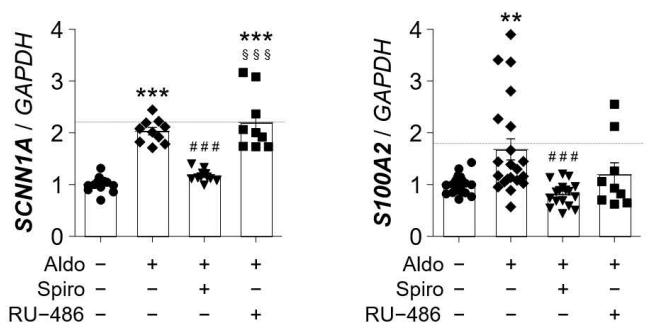

g

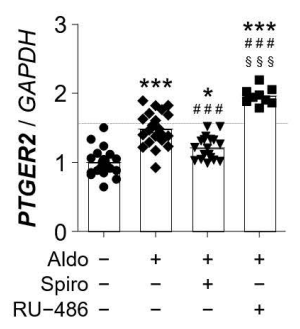

h

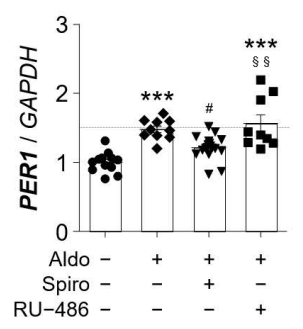

k

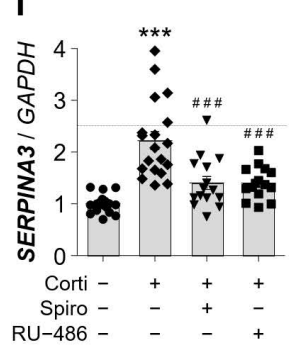

j
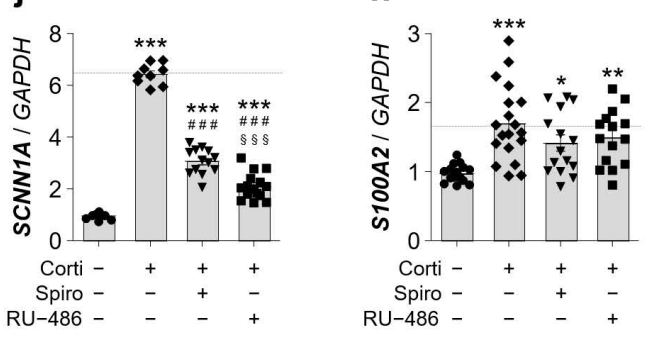

I
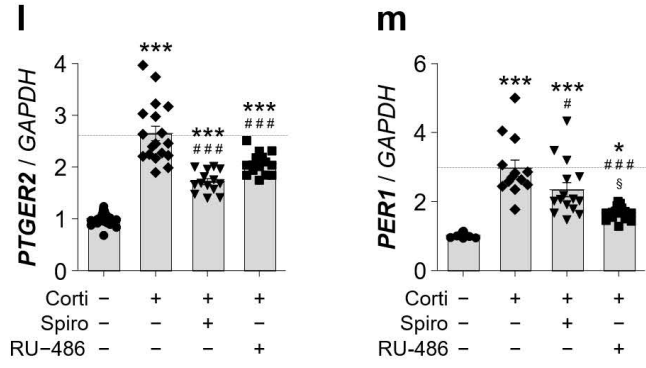

n

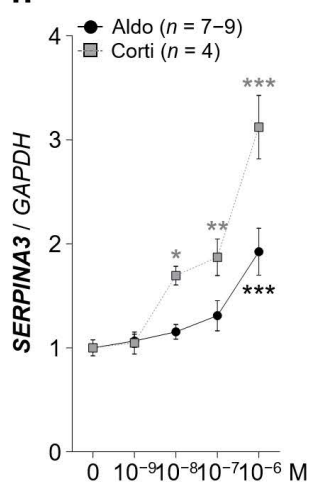

0

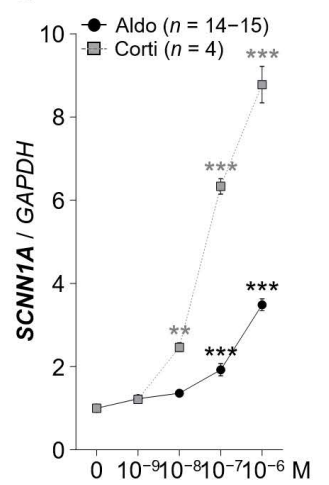

q

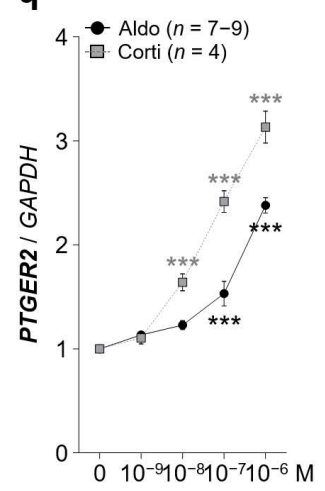

r

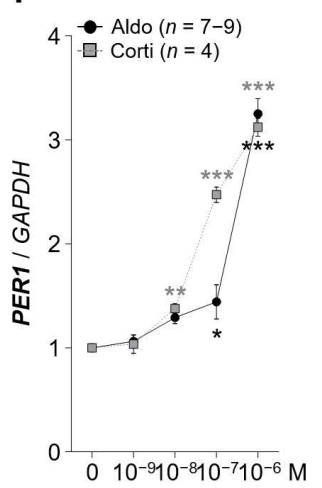

Figure 5. Aldosterone and cortisol up-regulated genes as predicted in RNA-Seq tested by RT-qPCR for validation. (a-c) Gene expression correlation analysis between RNA-Seq and RT-qPCR results generated in iRPE cells for the 3 experimental treatments aldosterone (aldo) $10^{-7} \mathrm{M}$ (a), cortisol (corti) $10^{-7} \mathrm{M}$ (b) and cortisol $10^{-7} \mathrm{M}+\mathrm{RU}-48610^{-5} \mathrm{M}$ (c). The Spearman's rank correlation or Pearson's correlation coefficient and the linear regression line (dashed blue line) are indicated. $(\mathbf{d}-\mathbf{h})$ Quantification by RT-qPCR of SERPINA3 (d), SCNN1A encoding $\alpha$-ENaC (e), S100A2 (f), PTGER2 (g) and PER1 (h) mRNA expression relative to GAPDH in iRPE cells following $24 \mathrm{~h}$ treatment of aldosterone $10^{-7} \mathrm{M} \pm$ spironolactone 
(spiro) $10^{-5} \mathrm{M}$ or RU-486 $10^{-5} \mathrm{M}$. (i-m) Quantification by RT-qPCR of SERPINA3 (i), SCNN1A (j), S100A2 (k), PTGER2 (l) and PER1 (m) mRNA expression relative to GAPDH in iRPE cells following $24 \mathrm{~h}$ treatment of cortisol $10^{-7} \mathrm{M} \pm$ spironolactone $10^{-5} \mathrm{M}$ or RU-486 $10^{-5} \mathrm{M}$. Dashed lines represent relative gene expression as predicted by the RNA-Seq analysis. Values are means \pm SEM. ${ }^{*} p<0.05,{ }^{* *} p<0.01,{ }^{* * *} p<0.001$, Aldo or Corti, Aldo or Corti + Spiro and Aldo or Corti + RU-486 versus untreated iRPE cells, ${ }^{\#} p<0.05,{ }^{\# \#} p<0.01,{ }^{\# \#} p<0.001$, Aldo or Corti + Spiro and Aldo or Corti + RU-486 versus Aldo or Corti, ${ }^{\S} p<0.05$, $\S_{\S} \$<0.001$, Aldo or Corti + RU-486 versus Aldo or Corti + Spiro. $(\mathbf{n}-\mathbf{r})$ Dose-dependency expression of SERPINA3 (n), SCNN1A (o), S100A2 (p), PTGER2 (q) and PER1 (r) mRNA relative to GAPDH following $24 \mathrm{~h}$ treatment of aldosterone or cortisol treatment in iRPE cells $(n=9)$. Untreated cells' mRNA expression was arbitrarily set to 1 . Values are means \pm SEM. ${ }^{*} p<0.05,{ }^{* *} p<0.01,{ }^{* * *} p<0.001$, relative values versus untreated condition. GAPDH, glyceraldehyde-3-phosphate dehydrogenase; SERPINA3, serpin family A member 3; Spiro, spironolactone; SCNN1A, sodium channel epithelial 1 alpha subunit; S100A2, S100 calcium-binding protein A2; PTGER2, prostaglandin E receptor 2; PER1, period circadian clock 1.
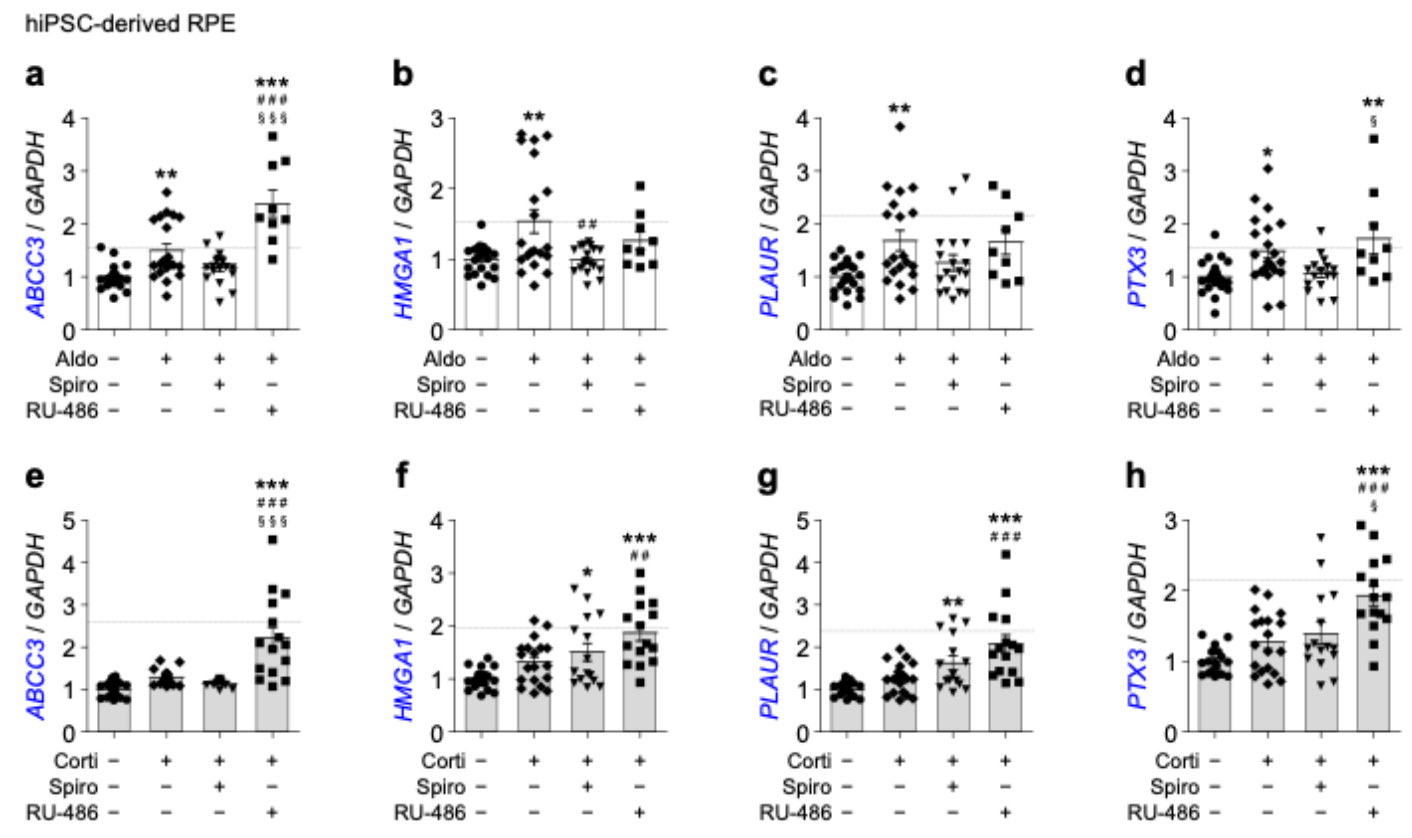

Rat RPE/choroid complex
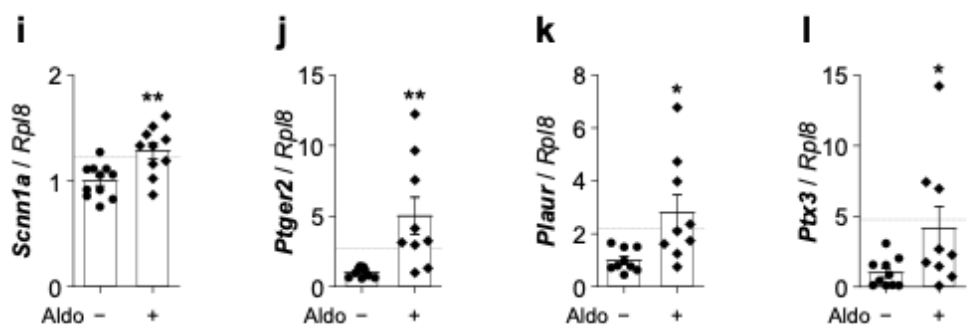

Scheme 1. Additional corticosteroid up-regulated genes of interest as predicted in RNA-Seq tested by RT-qPCR for validation. (a-h) Quantification by RT-qPCR of ABCC3 (a) and (e), HMGA1 (b) and (f), PLAUR (c) and (g) and PTX3 (d) and (h) mRNA expression relative to GAPDH in iRPE cells following $24 \mathrm{~h}$ treatment of aldosterone (aldo) $\left(10^{-7} \mathrm{M}\right)(\mathbf{a}-\mathbf{d})$ or cortisol (corti) $\left(10^{-7} \mathrm{M}\right)(\mathbf{e}-\mathbf{h}) \pm$ spironolactone (spiro) $\left(10^{-5} \mathrm{M}\right)$ or RU-486 $\left(10^{-5} \mathrm{M}\right)$. Dashed lines represent relative gene expression as predicted by the RNA-Seq analysis for the experimental condition aldosterone (a-d) or cortisol + RU-486 (e-h). (i-1) Quantification by RT-qPCR of Scnn1a (i), Ptger2 (j), Plaur (k) and Ptx3 (1) expression relative to Rpl8 in Lewis rat RPE-choroid complexes isolated from intravitreally aldosterone-injected $\left(10^{-7} \mathrm{M}\right)$ and sham-injected eyes. Dashed lines represent relative gene expression as predicted by the RNA-Seq analysis for the experimental condition aldosterone. Values are means \pm SEM. ${ }^{*} p<0.05,{ }^{* *} p<0.01,{ }^{* *} p<0.001$, Aldo or Corti, Aldo or Corti + Spiro and Aldo or Corti + RU-486 versus untreated iRPE cells or rats RPE/choroid complexes, ${ }^{\# \#} p<0.01,{ }^{\# \#} p<0.001$, Aldo or Corti + Spiro 
and Aldo or Corti + RU-486 versus Aldo or Corti, $\S p<0.05$, $\$ \S \S p<0.001$, Aldo or Corti + RU-486 versus Aldo or Corti + Spiro. GAPDH, glyceraldehyde-3-phosphate dehydrogenase; ABCC3, ATP-binding cassette subfamily C member 3; HMGA1, high-mobility group AT-hook 1; PLAUR and Plaur, urokinase plasminogen activator surface receptor; PTX3 and Ptx3, pentraxin 3; Scnn1a, sodium channel epithelial 1 alpha subunit; Ptger2, prostaglandin E receptor 2; Rpl8, ribosomal protein L8.

\section{5. $\alpha E N a C$ and S100A2 Protein Expression Was Increased by Aldosterone and Cortisol in iRPE Cells}

Immunostaining results show that SCNN1A (Figure 6a) and S100A2 (Figure 6b) protein expression was increased in iRPE cells following either aldosterone or cortisol treatments. Interestingly, SCNN1A was predominantly expressed on the apical side of iRPE cells as highlighted by the white arrowheads (Figure 6a). Furthermore, Western blot analysis demonstrated that both aldosterone (Figure 7a,b) and cortisol (Figure 7c,d) up-regulated the relative protein expression of S100A2 and PTGER2.
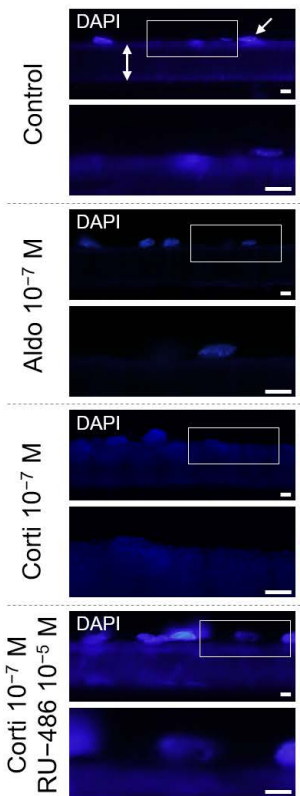
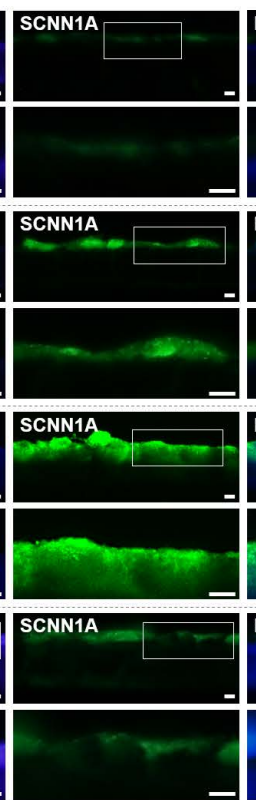
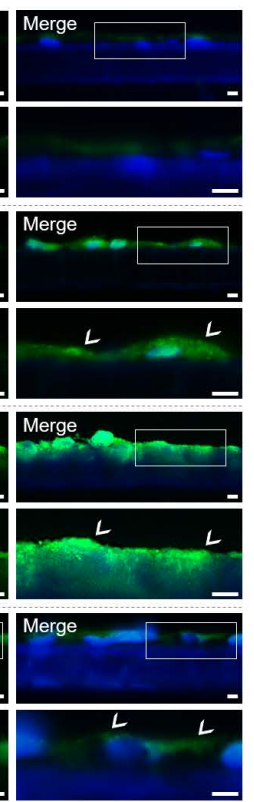

b
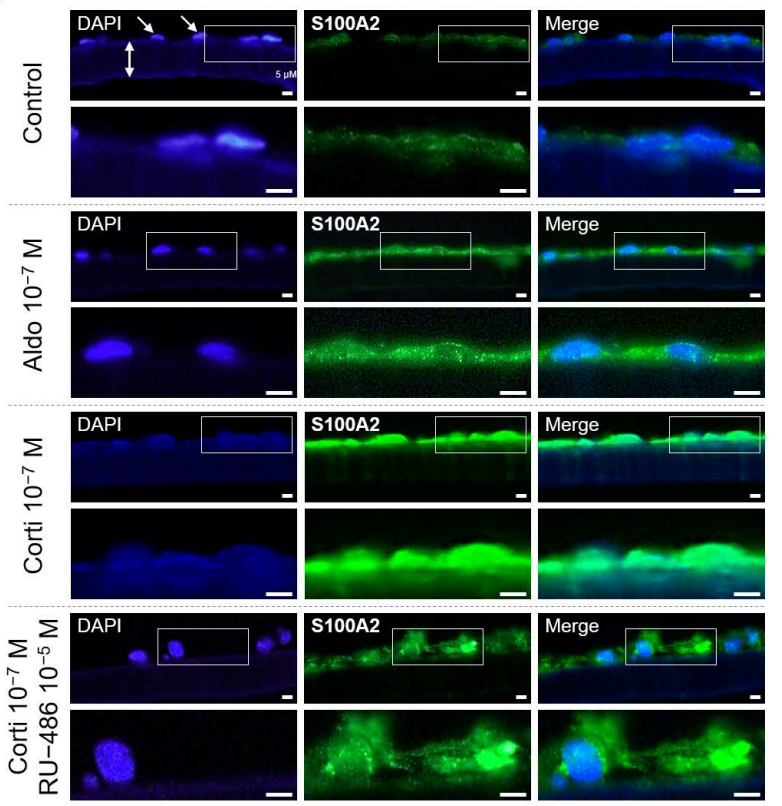

Figure 6. SCNN1A and S100A2 immunohistochemistry in iRPE cells. (a) and (b) Representative analysis by immunofluorescence of endogenous SCNN1A (a) and S100A2 (b) protein expression in iRPE cells cultured on transwell filters (double white arrows) following $24 \mathrm{~h}$ treatment of aldosterone (aldo) $10^{-7} \mathrm{M}$, cortisol (corti) $10^{-7} \mathrm{M}$ or cortisol $\left(10^{-7} \mathrm{M}\right) \pm \mathrm{RU}-486$ $\left(10^{-5} \mathrm{M}\right)$. SCNN1A and S100A2 staining is in green, and DAPI staining for cell nuclei (white arrows) is in blue, respectively. White arrowheads indicate apical staining (a). Scale bar: $30 \mu \mathrm{m}$. SCNN1A, sodium channel epithelial $1 \alpha$ subunit; S100A2, S100 calcium-binding protein A2. 
a

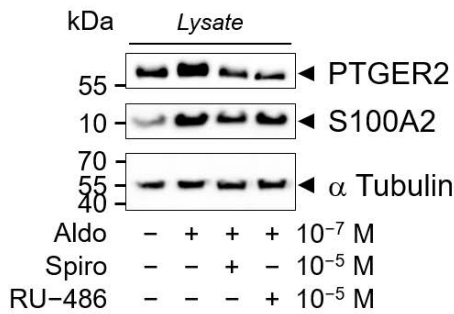

C

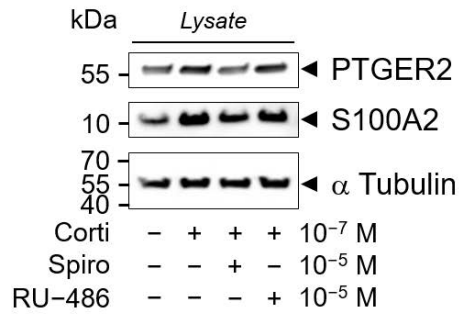

b

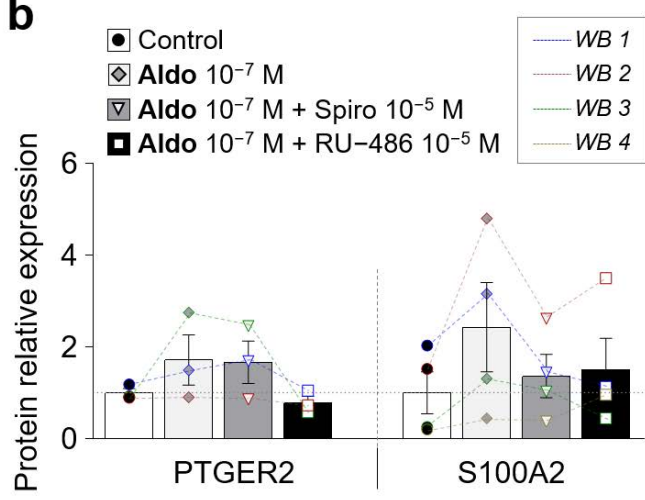

d

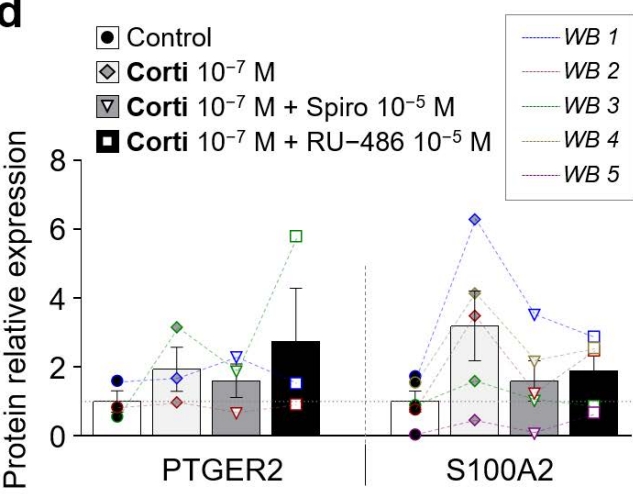

Figure 7. Western blot of PTGER2 and S100A2 in iRPE cells. (a) and (b) Western blot of PTGER2 and S100A2 protein expression in iRPE cells following $24 \mathrm{~h}$ treatment of aldosterone (aldo) $10^{-7} \mathrm{M}$ (a) or cortisol (corti) $10^{-7} \mathrm{M}$ (b) \pm spironolactone (spiro) $10^{-5} \mathrm{M}$ or RU-486 $10^{-5}$ M. $\alpha$-Tubulin is used as loading control. Arrows indicate the expected size of the $55 \mathrm{kDa}$ PTGER2, $15 \mathrm{kDa}$ S100A2 and $50 \mathrm{kDa} \alpha$-Tubulin proteins. (c,d) Bar graphs represent densitometric quantification of PTGER2 $(n=3)$ and S100A2 $(n=4-5)$ protein expression relative to $\alpha$-Tubulin levels in protein lysate (panel $\mathbf{a}$ and $\mathbf{b})$. Values are means \pm SEM. S100A2, S100 calcium-binding protein A2; PTGER2, prostaglandin E receptor 2.

\subsection{Corticosteroids Markedly Modified the Expression Pattern of Extracellular Proteins in iRPE Cells}

The Reactome pathway analysis revealed that extracellular matrix (ECM) proteoglycans, integrin cell surface interactions and degradation of the ECM terms were enriched in the ECM organization category (Figure 8a-c, Supplementary Tables S8-S10). Particularly, aldosterone down-regulated $F M O D, B G N$ and COL2A1 genes, while cortisol downregulated SPP1, ITGA11 and COL1A1 genes. Moreover, activation of the MR pathway down-regulated the expression of small leucine-rich proteoglycans such as biglycan, lumican and fibromodulin, known to be highly expressed in the RPE, Bruch membrane, choroid and sclera [32]. Cortisol and RU-486 co-treatment regulated numerous pathways suggesting that the activation of MR by cortisol has more biological consequences than activation of MR by aldosterone. Indeed, several pathways involved in the control of cell proliferation (cell cycle category) were down-regulated (Figure 8c, Supplementary Table S10). In the homeostasis category, the basigin interactions pathway known to be associated with the synthesis of several matrix metalloproteinases, angiogenesis via stimulation of VEGF production and glucose uptake was up-regulated. Other categories in the Reactome pathway analysis to be significantly represented in corticosteroid-treated iRPE cells were genes involved in metabolism of proteins, signal transduction and metabolism.

With regard to the biological process GO analysis, cell communication, anatomical structure development, cell adhesion, cellular metabolic process, cell death, regulation of biological quality, cellular component organization or biogenesis and cell cycle were 
the most represented categories enriched in corticosteroid-treated iRPE cells (Figure 9a-c, Supplementary Tables S11-S13). Regarding the molecular function GO, the most represented categories in the aldosterone, cortisol and cortisol + RU-486 experimental conditions included signaling receptor activity, protein binding, transmembrane transporter activity, ECM binding and oxidoreductase activity (Scheme 2, Supplementary Tables S14-S16). Finally, concerning the cellular component GO, categories involved at the membrane, cell junction, extracellular region, cell periphery and intracellular anatomical structure level were represented in corticosteroid-treated iRPE cells, which comprised enrichments of integrin complex, focal adhesion, proteinaceous ECM, ECM and microvillus as terms of interest (Scheme 3, Supplementary Tables S17-S19).

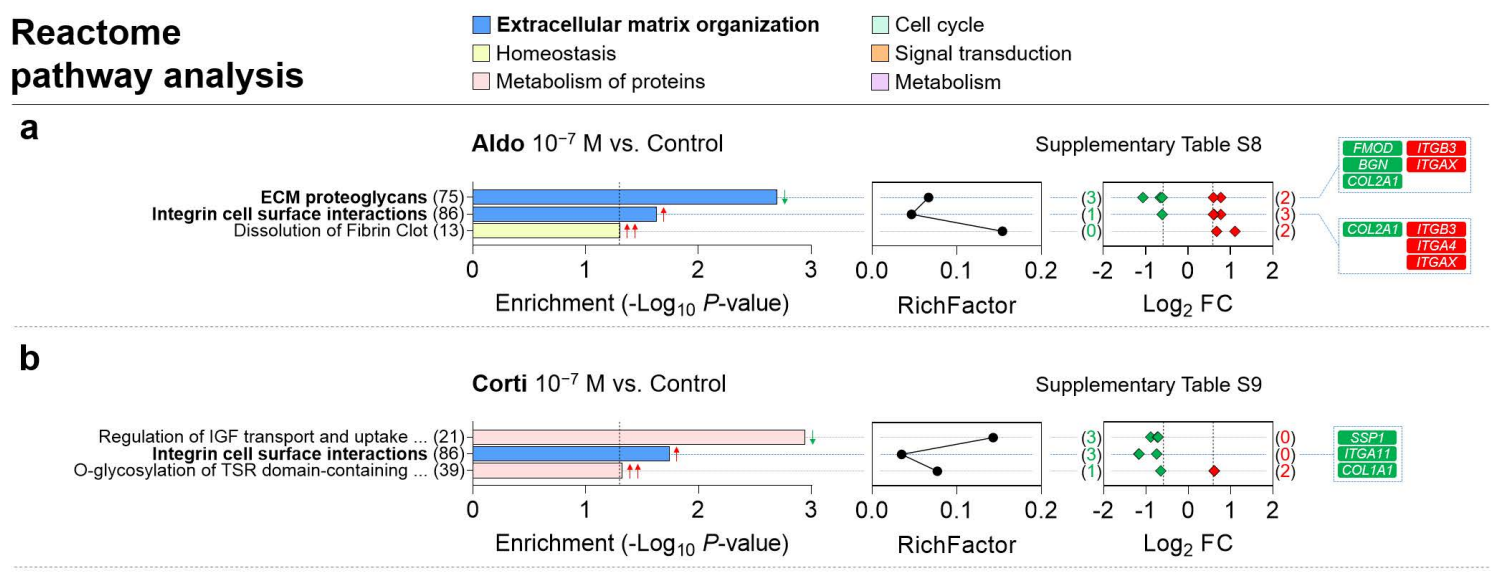

C

Corti $10^{-7} \mathrm{M}+\mathbf{R U}-\mathbf{4 8 6} 10^{-5} \mathrm{M}$ vs. Control Supplementary Table S10

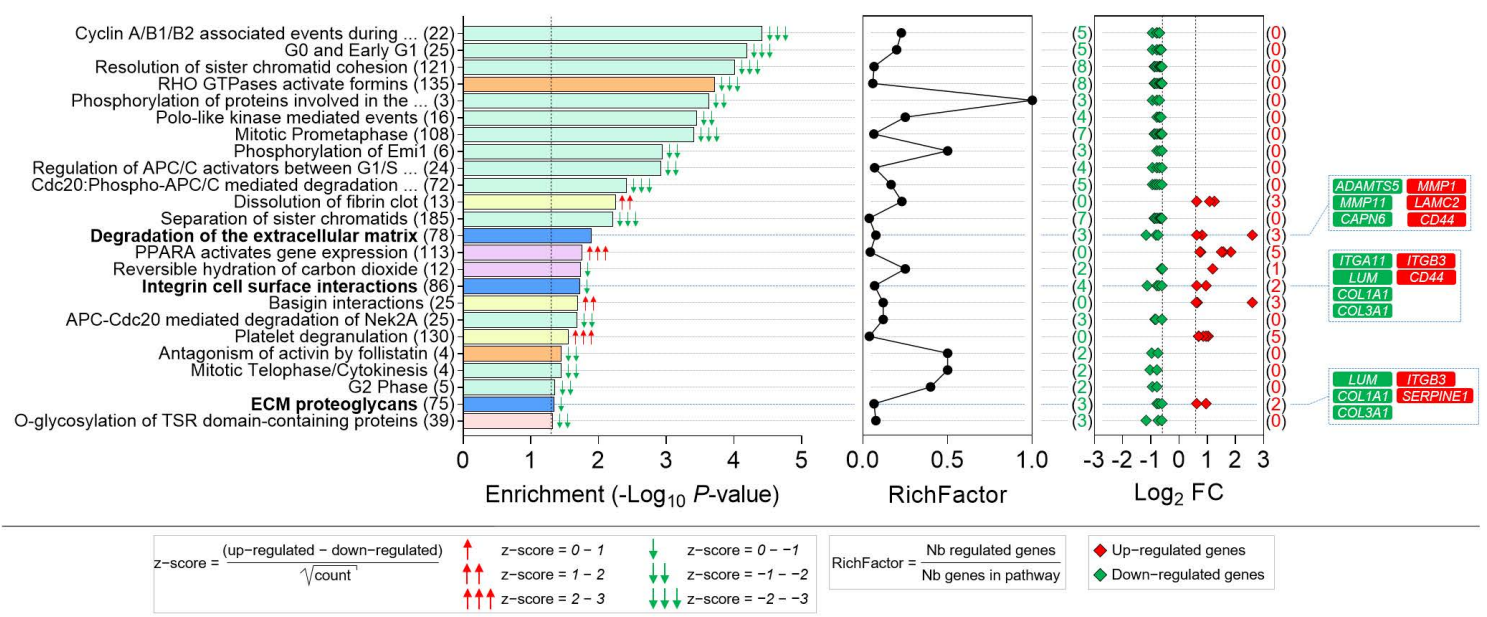

Figure 8. ECM organization, homeostasis, metabolism of proteins, cell cycle, signal transduction and metabolism are the most represented Reactome pathway categories enriched in corticosteroid-treated iRPE cells. (a-c) Specific corticosteroidregulated enriched Reactome pathways as predicted by bioinformatic enrichment analysis with their respective RichFactor value and the number of differentially expressed genes (DEGs) involved in the pathway, in iRPE cells treated for $24 \mathrm{~h}$ with aldosterone (aldo) $10^{-7} \mathrm{M}$ (a), cortisol (corti) $10^{-7} \mathrm{M}\left(\mathbf{b}\right.$ ) or cortisol $10^{-7} \mathrm{M}+\mathrm{RU}-48610^{-5} \mathrm{M}$ (c) and compared to untreated cells. Reactome pathways are considered enriched if $p$ value is $<0.05$ and the number of regulated genes in the pathways is 22. $p$-values, and fold-change (FC) values are represented in a $-\log _{10}$ and a $\log _{2}$ scale, respectively. Most represented enriched Reactome pathways and pathways of interest are highlighted in bold. Based on z-score values, green and red arrows in the left panel indicate down- and up-regulated pathways, respectively. Numbers between parentheses placed after enriched Reactome pathway names in the left panels represent the total number of genes implicated in the respective pathway. Numbers between parentheses in the right panels indicate the number of down- (in green) and up-regulated (in red) genes in their corresponding pathway. Corticosteroid-regulated genes in Reactome pathways of interest are listed in the right panel (Corti $10^{-7} \mathrm{M}+\mathrm{RU}-48610^{-5} \mathrm{M}$ vs. Control). 


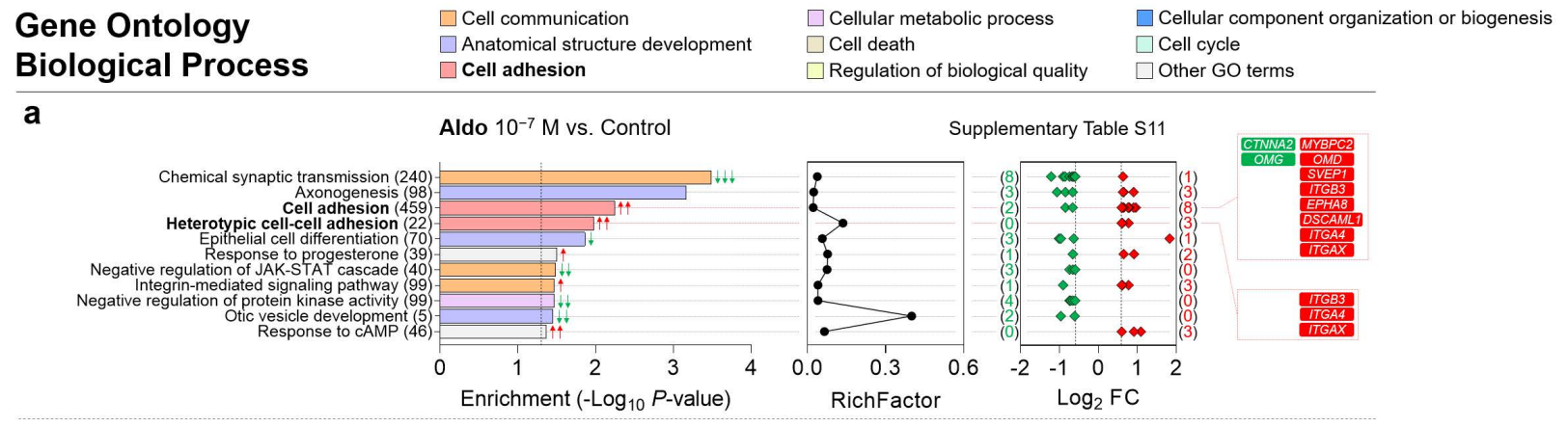

b

Corti $10^{-7} \mathrm{M}$ vs. Control

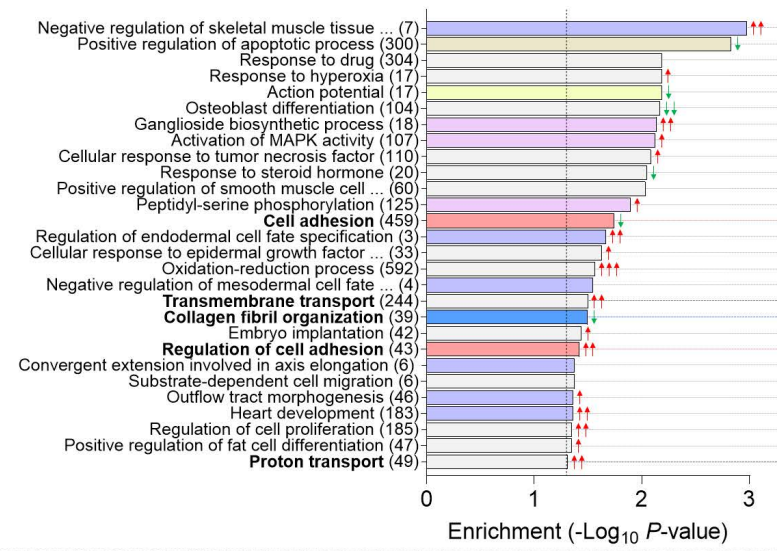

Supplementary Table S12

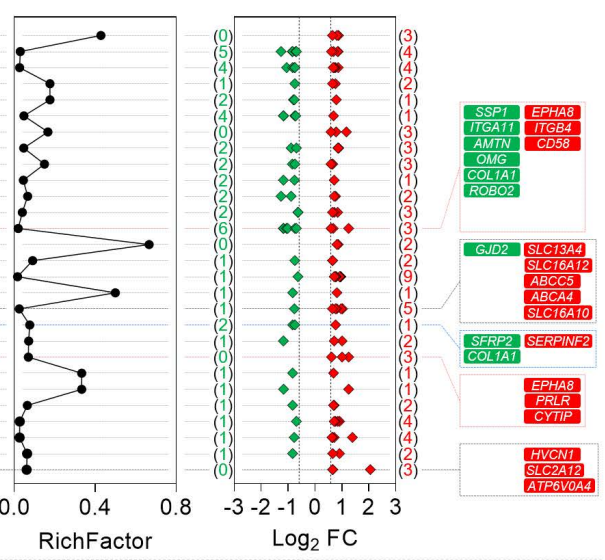

C

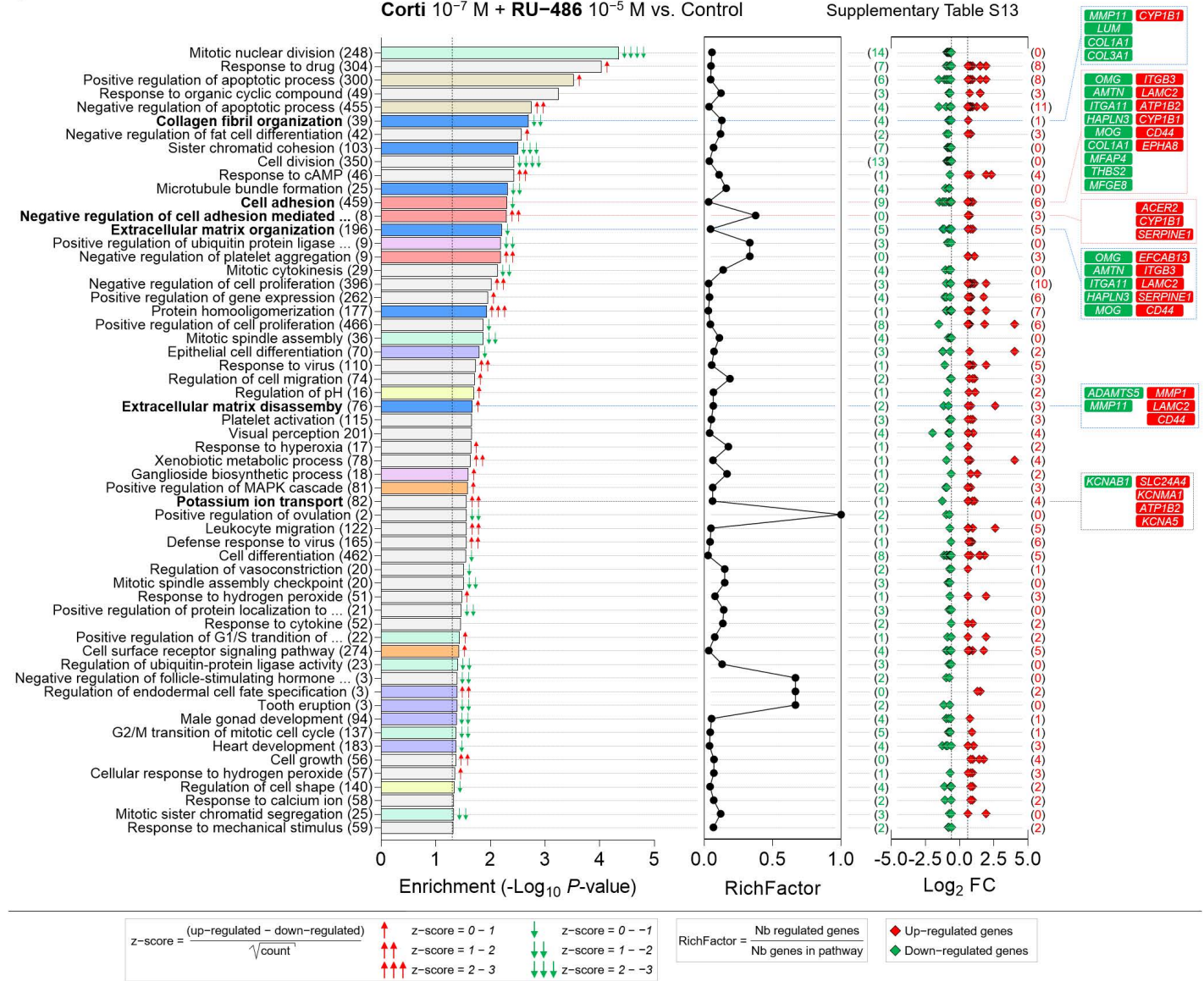

Figure 9. Cell communication, anatomical structure development, cell adhesion, cellular metabolic process, cell death, 
regulation of biological quality, cellular component organization or biogenesis and cell cycle are the most represented biological process GO categories enriched in corticosteroid-treated iRPE cells. (a-c) Specific corticosteroid-regulated enriched biological process gene ontology (GO) terms as predicted by bioinformatic enrichment analysis with their respective RichFactor value and the number of differentially expressed genes (DEGs) involved in the process, in iRPE cells treated for $24 \mathrm{~h}$ with aldosterone (aldo) $10^{-7} \mathrm{M}$ (a), cortisol (corti) $10^{-7} \mathrm{M}$ (b) or cortisol $10^{-7} \mathrm{M}+\mathrm{RU}-48610^{-5} \mathrm{M}$ (c) and compared to untreated cells. Biological process GO terms are considered enriched if $p$ value is $<0.05$ and the number of regulated genes in the pathways is $\geq 2$. $p$-values and fold-change (FC) values are represented in a $-\log _{10}$ and a $\log _{2}$ scale, respectively. Most represented enriched biological process GO terms and GO terms of interest are highlighted in bold. Based on z-score values, green and red arrows in the left panel indicate down- and up-regulated GO terms, respectively. Numbers between parentheses placed after enriched biological process GO term names in the left panels represent the total number of genes implicated in the respective GO term. Numbers between parentheses in the right panels indicate the number of down- (in green) and up-regulated (in red) genes in their corresponding GO term. Corticosteroid-regulated genes in biological process GO terms of interest are listed in the right panel.

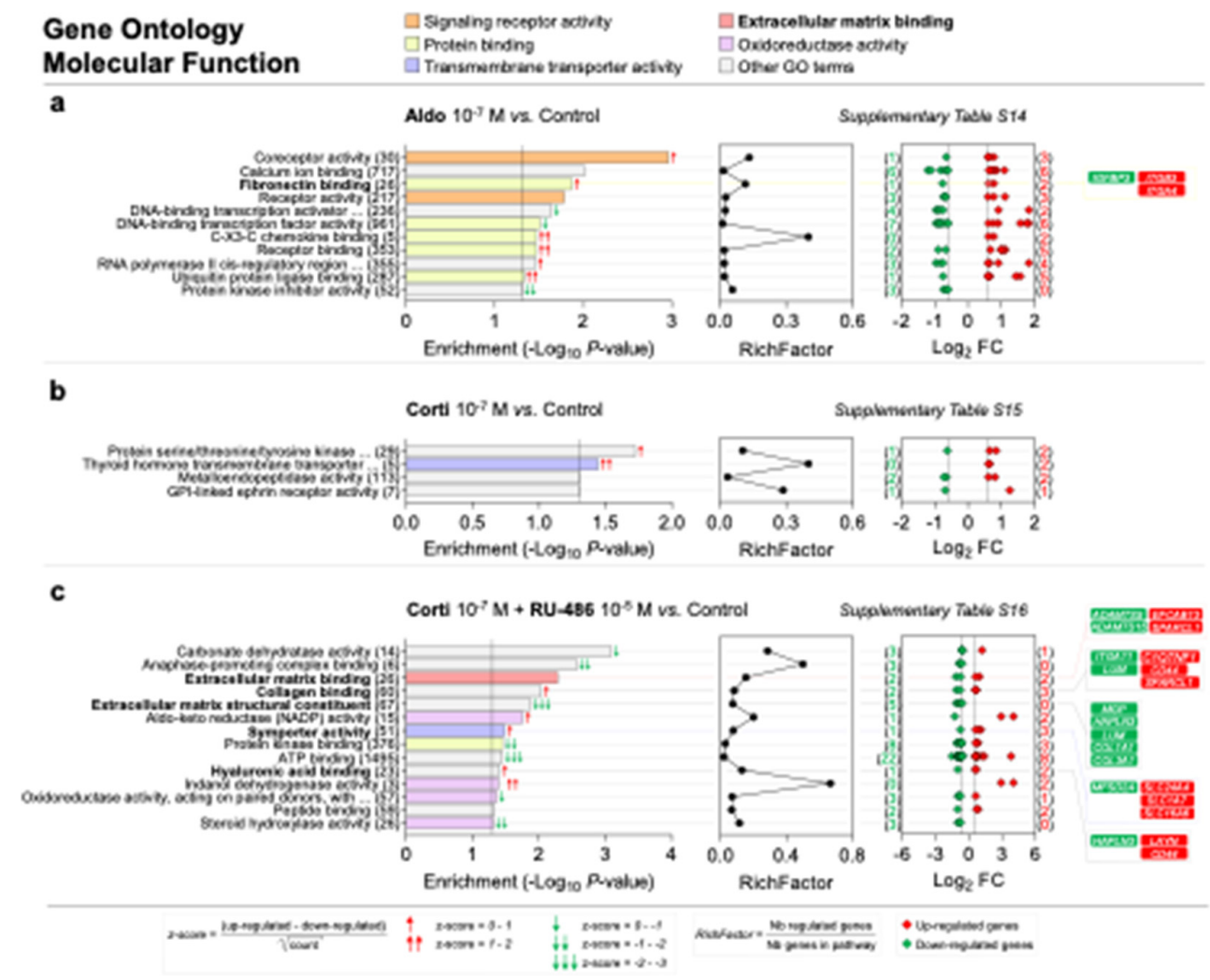

Scheme 2. Signaling receptor activity, protein binding, transmembrane transporter activity, ECM binding and oxidoreductase activity are the most represented molecular function GO categories enriched in corticosteroid-treated iRPE cells. $(\mathbf{a}-\mathbf{c})$ Specific corticosteroid-regulated enriched molecular function gene ontology (GO) terms as predicted by bioinformatic enrichment analysis with their respective RichFactor value and the number of differentially expressed genes (DEGs) involved in the function, in iRPE cells treated for $24 \mathrm{~h}$ with aldosterone (aldo) $10^{-7} \mathrm{M}$ (a), cortisol (corti) $10^{-7} \mathrm{M}$ (b) or cortisol $10^{-7} \mathrm{M}+\mathrm{RU}-48610^{-5} \mathrm{M}$ (c) and compared to untreated cells. Molecular function GO terms are considered enriched if $p$ value is $<0.05$ and the number of regulated genes in the pathways is $\geq 2$. $p$-values and fold-change (FC) values are represented in a $-\log _{10}$ and $\log _{2}$ scale, respectively. Most represented enriched molecular function GO terms are regrouped into five categories: signaling receptor activity, protein binding, transmembrane transporter activity, extracellular matrix binding and oxidoreductase activity; GO terms of interest are highlighted in bold. Based on z-score values, green and red arrows in the left panel indicate down- and up-regulated GO terms, respectively. Numbers between parentheses placed after enriched molecular function GO term names in the left panels represent the total number of genes implicated in the respective GO term. Numbers between parentheses in the right panels indicate the number of down- (in green) and up-regulated (in red) genes in their corresponding GO term. Corticosteroid-regulated genes in molecular function GO terms of interest are listed in the right panel. 

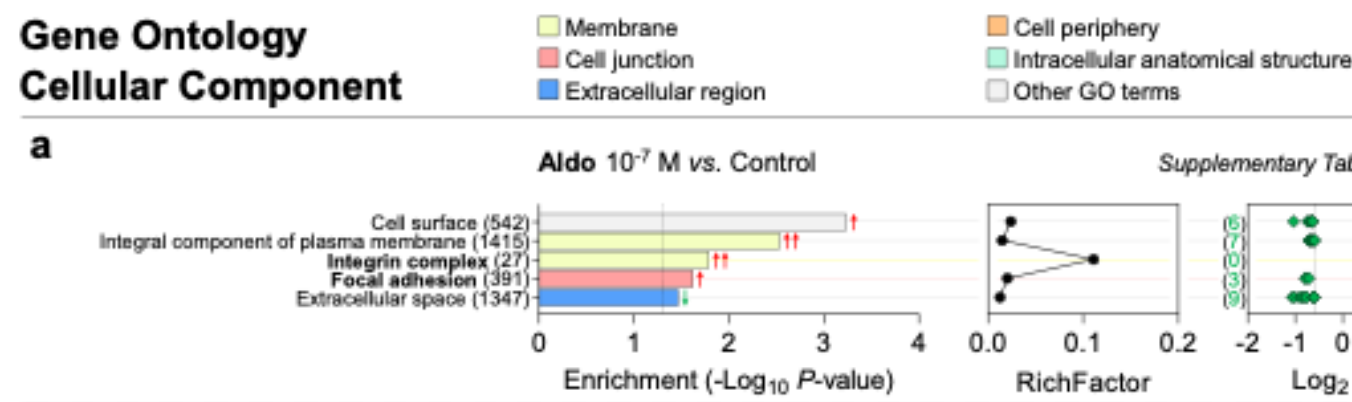

b
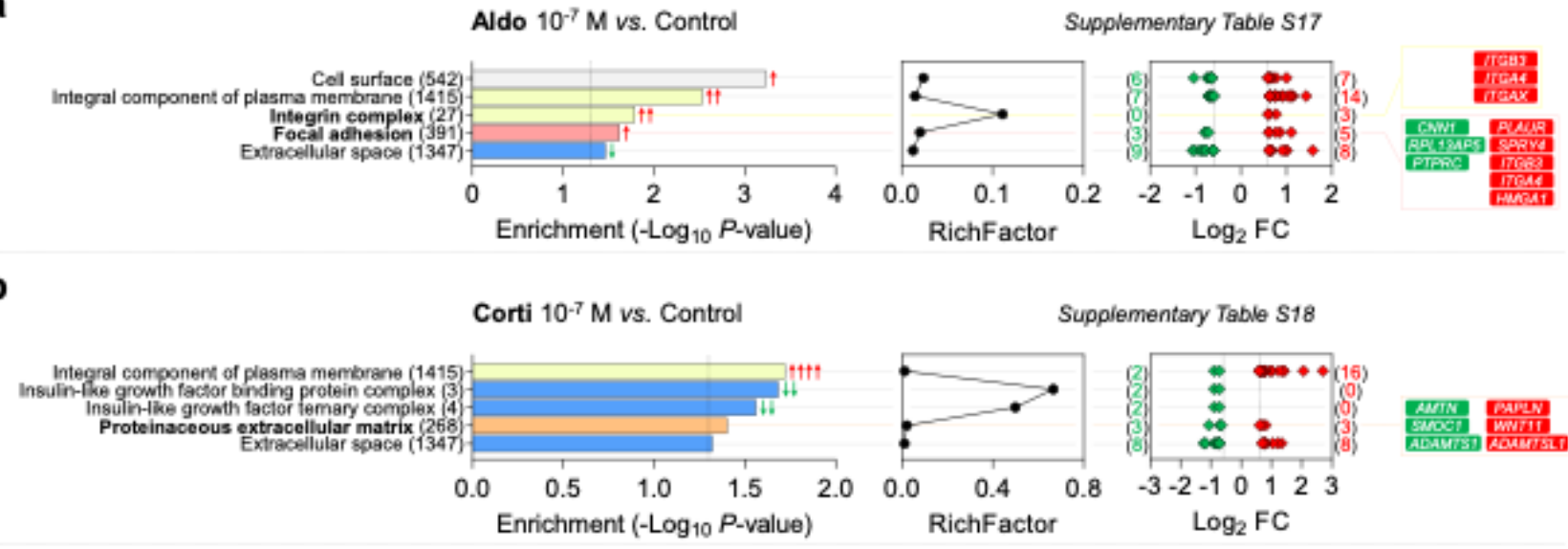

c

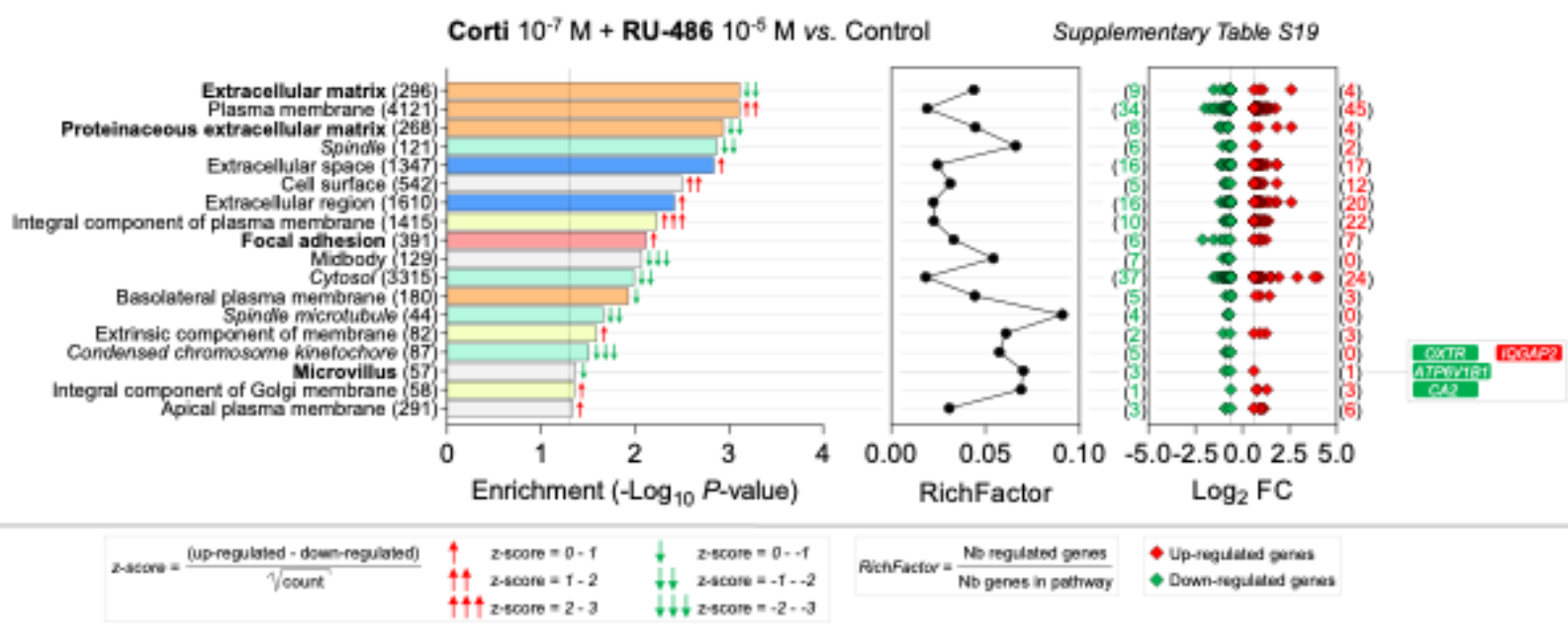

Scheme 3. Membrane, cell junction, extracellular region, cell periphery and intracellular anatomical structure are the most represented cellular component GO categories enriched in corticosteroid-treated iRPE cells. (a-c) Specific corticosteroidregulated enriched cellular component gene ontology (GO) terms as predicted by bioinformatic enrichment analysis with their respective RichFactor value and the number of differentially expressed genes (DEGs) involved in the component, in iRPE cells treated for $24 \mathrm{~h}$ with aldosterone (aldo) $10^{-7} \mathrm{M}\left(\mathbf{a}\right.$ ), cortisol (corti) $10^{-7} \mathrm{M}$ (b) or cortisol $10^{-7} \mathrm{M}+\mathrm{RU}-486$ $10^{-5} \mathrm{M}(\mathrm{c})$ and compared to untreated cells. Cellular component GO terms are considered enriched if $p$ value is $<0.05$ and the number of regulated genes in the pathways is $\geq 2$. $p$-values and fold-change (FC) values are represented in a $-\log _{10}$ and a $\log _{2}$ scale, respectively. Most represented enriched cellular component GO terms are regrouped into five categories: membrane, cell junction, extracellular region, cell periphery and intracellular anatomical structure; GO terms of interest are highlighted in bold. Based on z-score values, green and red arrows in the left panel indicate down- and up-regulated GO terms, respectively. Numbers between parentheses placed after enriched cellular component GO term names in the left panels represent the total number of genes implicated in the respective GO term. Numbers between parentheses in the right panels indicate the number of down- (in green) and up-regulated (in red) genes in their corresponding GO term. Corticosteroid-regulated genes in cellular component GO terms of interest are listed in the right panel.

2.7. Retinal Phenotype of Mice Overexpressing the Human MR Showed Abnormalities at the Level of the RPE and the Choroidal Vasculature

While no difference in murine $\mathrm{Nr} 3 \mathrm{c} 2$ (Figure 10a) and $\mathrm{Nr} 3 \mathrm{c1}$ (Figure 10b) expression was observed between P1.hMR and control animals, the human NR3C2 transgene was highly expressed in the RPE/choroid complex of P1hMR mice (Figure 10c). As expected, no expression of the transgene was detected in wild-type control mice. In 6-weeks-old mice, in vivo spectral-domain optical coherence tomography (SD-OCT) imaging showed 
a

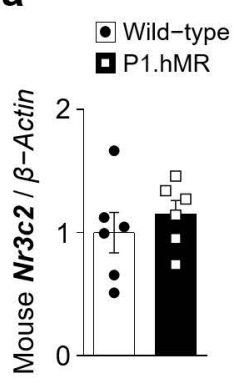

b

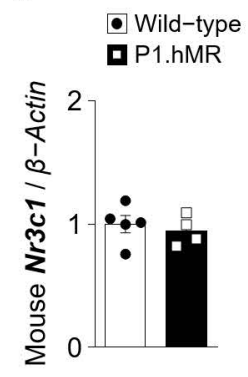

a normal structure of the inner retina in P1.hMR mice (Figure 10e,f). Nevertheless, an increased thickness of the choroid (Figure 10e,f, insets 3,4 and 6) and hyperreflective and dense irregular areas at the level of the RPE (Figure 10e,f, insets 3-5) were observed. Epithelial and choroidal abnormal features of the outer retinal structure were absent in control animals (Figure 10d, insets 1 and 2).
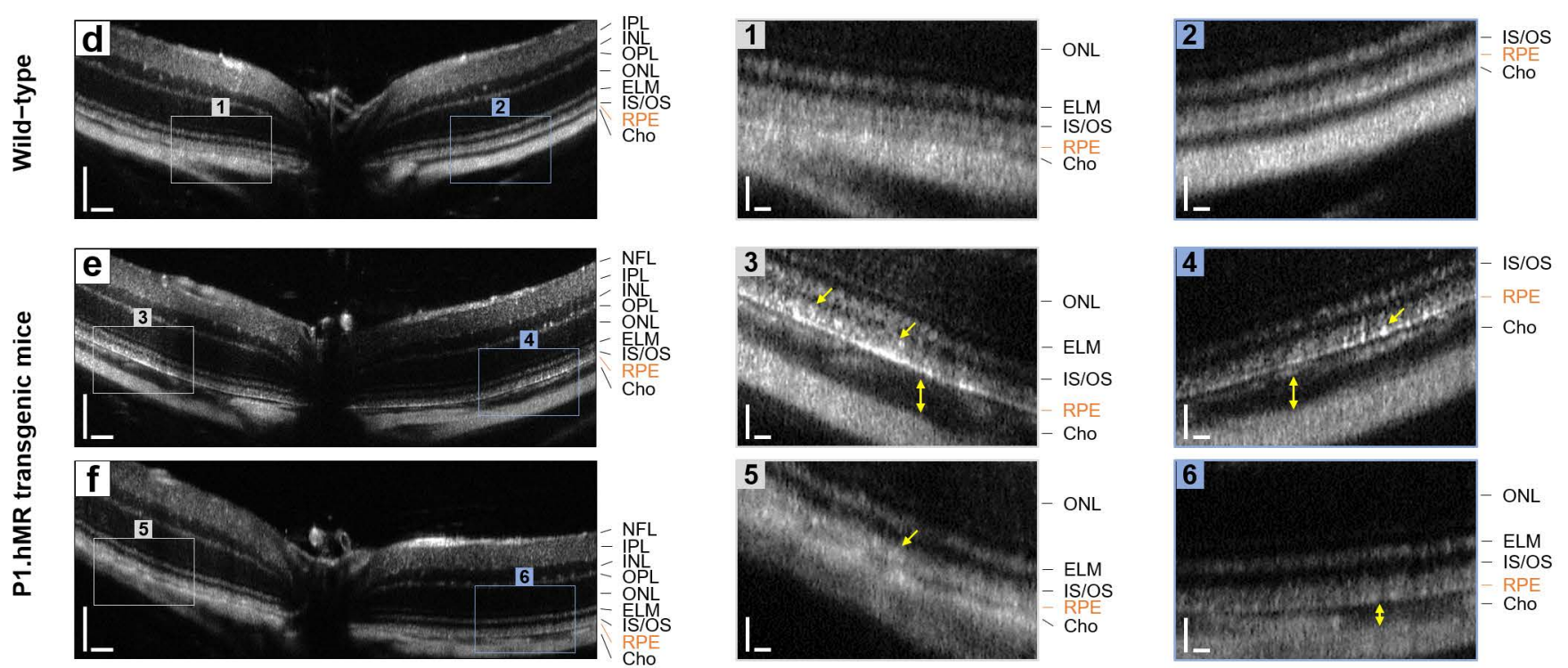

Figure 10. Clinical phenotype of P1.hMR transgenic mice. (a-c) Quantification by RT-qPCR of the mouse Nr3c2 encoding MR (a), the mouse Nr3c1 encoding GR (b) and the human Nr3c2 (c) mRNA to $\beta$-Actin in RPE/choroid complexes ( $n=4-6$ eyes per condition) from wild-type animals and mice overexpressing a human MR P1.hMR transgene. Values are means \pm SEM. Unpaired $t$-test with Welch's correction. ${ }^{* *} p<0.01$. (d-f) Representative in vivo MICRON III image-guided optical coherence tomography images of B-scans passing through the optic nerve of retina from wild-type (d) or transgenic P1.hMR $(\mathbf{e}, \mathbf{f})$ mice showing increased choroidal thickness (yellow double arrows) and irregular and hyper-reflective signal at the level of the RPE (yellow arrows). Scale bar: $100 \mu \mathrm{m}$ (d-f) and $25 \mu \mathrm{m}$ (insets 1-6). NFL, nerve fiber layer; IPL, inner plexiform layer; INL, inner nuclear layer; OPL, outer plexiform layer, ONL, outer nuclear layer; ELM, external limiting membrane; IS, inner segment; OS, outer segment; RPE, retinal pigment epithelium; Cho, choroid.

Histological section analysis confirmed that as compared to wild-type mice (Figure 11a and inset 1), the choroidal thickness in P1.hMR mice was increased, as shown by enlarged choroidal vessels, inducing RPE cell displacement and focal retinal detachment (Figure 11b,c,e insets 2, 3 and 5). Moreover, RPE cells appeared swollen with intracellular vacuole accumulation (Figure $11 \mathrm{~b}-\mathrm{e}$, insets $2-5$ ). In addition, inner and outer segments of the photoreceptor were elongated (Figure $11 \mathrm{~b}, \mathrm{c}, \mathrm{e}$, insets 2, 3 and 5). The surface area of the choroid ( $2.367 \pm 0.719$ vs. $\left.1.402 \pm 0.098 \mathrm{~mm}^{2}\right)$ (Figure 11f), photoreceptor segments $\left(4.711 \pm 1.141\right.$ vs. $\left.3.661 \pm 0.414 \mathrm{~mm}^{2}\right)$ (Figure $\left.11 \mathrm{~g}\right)$ and RPE thickness $(4.3 \pm 0.22$ vs. $3.6 \pm 0.6 \mu \mathrm{m}$ ) (Figure 11h) were significantly increased in P1.hMR mice as compared to control eyes. Whist albumin localized only into choroidal vessels and faintly in RPE 

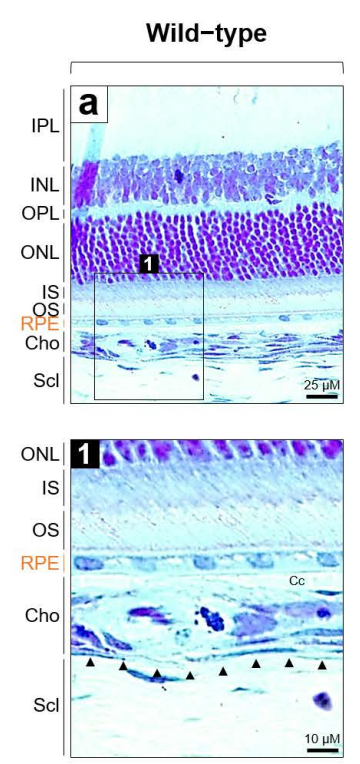

cells in wild-type mice, it showed accumulation within and between RPE cells, in the choroidal stroma and in the photoreceptor segments in P1.hMR transgenic mice (Scheme 4). Overexpression of the human MR encoded by the NR3C2 gene in the retina, without any other exogenous stress, induced progressive pathology, mostly observed at the level of the RPE and the choroid.
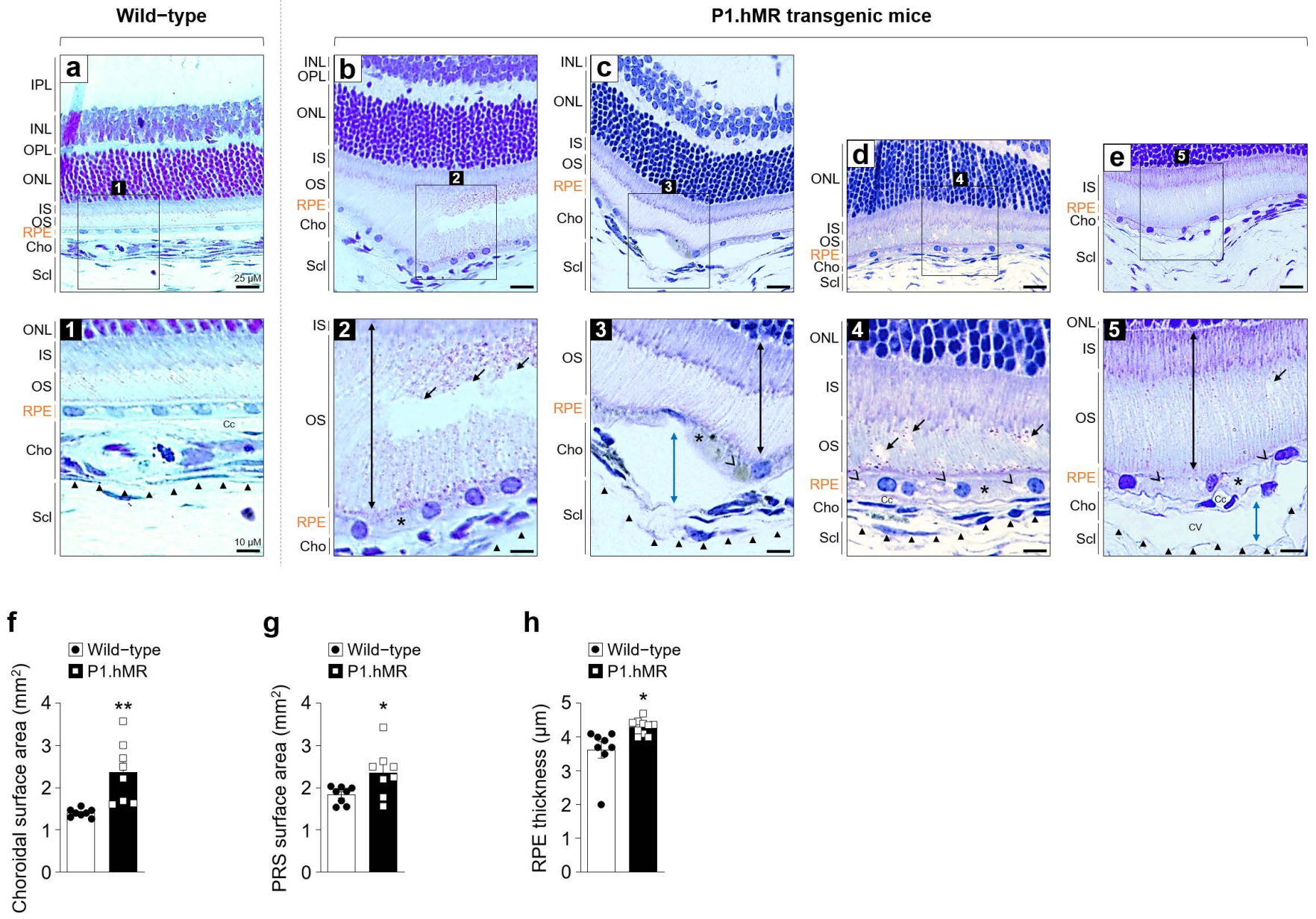

Figure 11. Histologic phenotype of P1.hMR mice. (a-e) Representative histologic sections of the retina from wild-type and P1.hMR transgenic mice at nine months of age. Sections are stained with toluidine blue. Black triangles delineate the limit between the choroid and the sclera. Inset (1) showed normal mouse outer retina. Insets (2-5) show histological regions where choroidal vessels are dilated (blue double arrows), RPE cells are swollen (black asterisks) with accumulation of vacuoles (black arrowheads), and the outer retina is disorganized by fluid accumulation (black arrows) and elongation of the inner and outer segments of photoreceptors (black double arrows). Scale bar: $25 \mu \mathrm{m}(\mathbf{a}-\mathbf{e})$ and $10 \mu \mathrm{m}(\mathbf{1}-\mathbf{5})$. (f-h) Choroidal surface area (f), photoreceptor segments surface area (g) and RPE thickness (h) were quantified on retina sections from wild-type and P1.hMR transgenic mice ( $n=8$ eyes). Values are means \pm SEM. Unpaired $t$-test with Welch's correction. ${ }^{*} p<0.05,{ }^{* *} p<0.01$. P1, proximal functional alternative promoter 1 upstream of the first two untranslated exons $1 \alpha$ and $1 \beta$ of the hMR gene; IPL, inner plexiform layer; INL, inner nuclear layer; OPL, outer plexiform layer, ONL, outer nuclear layer; IS, inner segment; OS, outer segment; RPE, retinal pigment epithelium; Cho, choroid; Scl, sclera; Cc, choriocapillaris; CV, choroidal vessel; PRS, photoreceptor segments. 


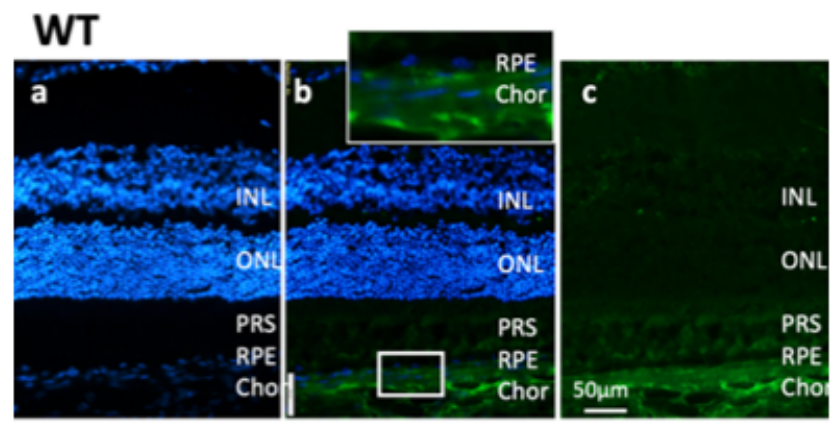

\section{P1hMR}
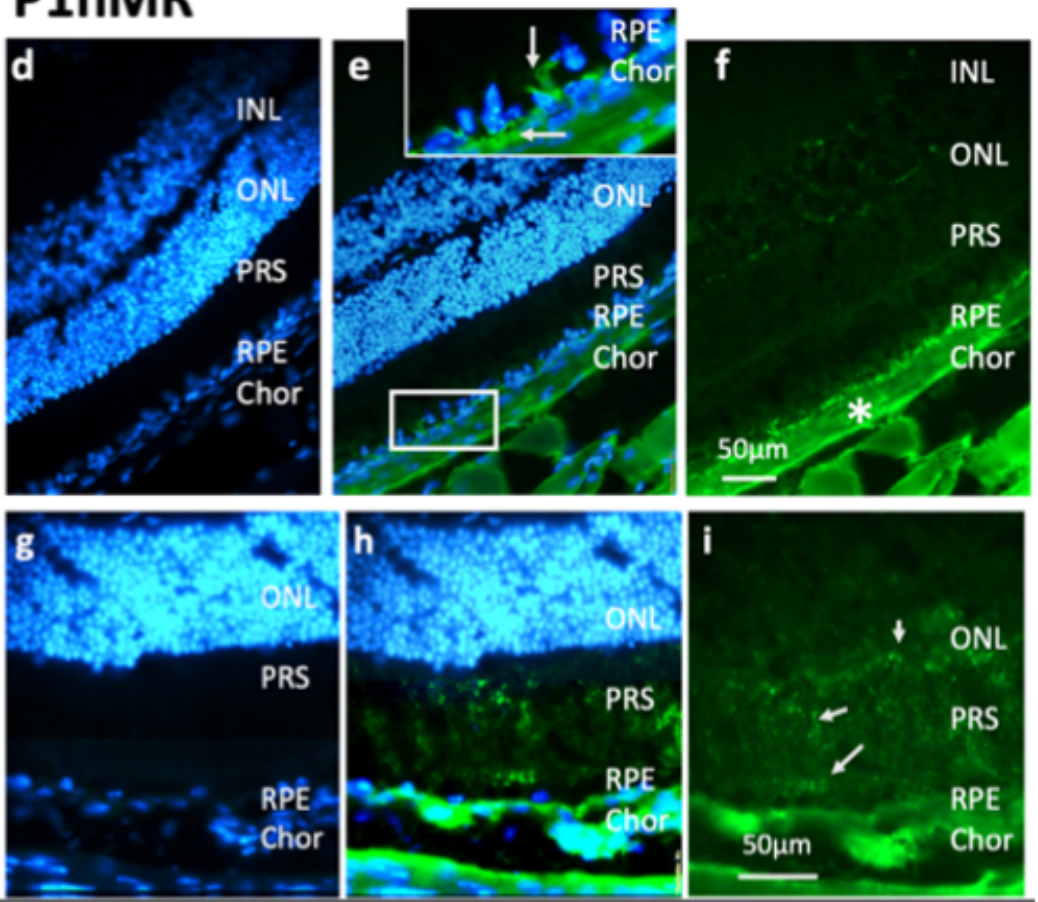

Scheme 4. Albumin accumulates within RPE cells and outer retina in P1.hMR transgenic mice. (a-i) Albumin immunostaining (in green) on retinal cryosections from wild-type (WT, a-c) and P1.hMR transgenic (d-i) mice. Cell nuclei are stained with DAPI (in blue). White arrows in (e, inset) and the white asterisk in (f) indicate accumulation of albumin in P1.hMR mice within RPE cells and in the choroidal stroma, respectively. Focal albumin staining is observed within the outer retina and particularly at the level of photoreceptor segments (g-i, arrows). INL, inner nuclear layer; ONL, outer nuclear layer; PRS, photoreceptor inner and outer segments; RPE, retinal pigment epithelium; Chor, choroid.

\section{Discussion}

The iRPE model stably expresses functional MR and GR and expresses known target genes upon corticoid exposure. Although the lowest aldosterone dose required to induce the expression of target genes was higher than expected, specificity of MR activation was demonstrated by the inhibitory effect of the MR antagonist spironolactone and by the dose-dependent effect of aldosterone on the expression of several genes such as SERPINA3, SCNN1A, S100A2, PTGER2 and PER1. The model is thus appropriate to study GR and MR transcriptomic regulations using specific ligands. In humans, aldosterone was below detectable levels in ocular media, suggesting control of its entry in the eye, as it was described in the brain $[33,34]$. Cortisol should thus be the preferential ligands for GR and MR in RPE cells in vivo although it cannot be excluded that aldosterone could stimulate RPE cells from their basolateral. 
In cortisol-treated cells, the number of significantly up-regulated genes was higher than the number of down-regulated genes. The contrary was observed in aldosterone- and cortisol + RU486-treated cells, indicating that MR activation represses rather than induces gene expression.

A subset of genes, regulated in a similar manner in all three experimental treatments, results from both GR and MR activation. Amongst those genes, CXCR4 and PTGER2 encode receptors that upon activation by their specific ligand SDF-1 and PGE2 can alter RPE functions. SDF-1 binding to CXCR4 induces RPE migration and contributes to retinal inflammation and choroidal neovascularization [35] whilst PGE2 induces RPE contraction and disruption of its barrier function [36]. In addition, PGE2 inhibits the ingestion of rod outer segments by RPE cells [37]. Up-regulation of CXCR4 and PTGER2 expression could alter RPE functions in a pro-inflammatory environment when their ligands are produced. HVCN1 encodes a voltage-gated proton channel that regulates the decrease in $\mathrm{pH}$ and reactive oxygen species burst induced by phagocytosis [38,39], a rhythmic process, regulated by clock genes in RPE cells [40]. Interestingly both aldosterone and cortisol up-regulated the expression of the clock gene PER1, in a dose-dependent manner. Cortisol could contribute to the circadian regulation of photoreceptors' outer segment recycling. The role of S100A2, recognized as a bad prognosis biomarker in cancer [41], is not known in the eye. S100A2 was shown to inhibit transforming growth factor- $\beta 1$ (TGF- $\beta 1$ )-induced epithelial-mesenchymal transition (EMT) in lung epithelial cells [42] and, upon oxidative stress, to translocate into the cytoplasm and delay keratinocytes cell death [43]. In iRPE cells, while cortisol favored the nuclear retention of the protein, aldosterone, and cortisol + RU486 rather induced its cytoplasmic translocation, suggesting differential effects of GR or MR activation on S100A2 activities.

The Reactome and GO analysis showed the important role of GR and MR activation in RPE cell differentiation. SERPINA3 encodes alpha- 1 antichymotrypsin (ACT), which inhibits the activity of the serine proteases cathepsin $G$ and chymase, secreted from mast cells, that are abundant in the choroid. Chymase activates matrix metalloproteinase (MMP)9 and TGF- $\beta$ that are essential for Bruch membrane maintenance and for extracellular matrix (ECM) [44]. All these genes encode proteins that intervene in RPE differentiation and adhesion and in RPE phagocytosis. Finally, SCNN1A, encoding alpha-ENaC- channel, expressed in RPE cells [45] is up-regulated by cortisol and by aldosterone as previously shown [16,21]. Immunohistochemistry of alpha-ENaC- performed on transversal sections of iRPE cells confirmed that aldosterone and cortisol increased its expression particularly toward the apical side.

Genes that were down-regulated by three corticosteroid treatments are calponin 1 (CNN1), somatostatin (SST), gap junction protein delta-2 (GJD2), and oligodendrocyte myelin glycoprotein $(O M G)$. Calponin's role in RPE cells is unknown. Somatostatin, whose receptors are expressed in RPE cells [46], protects its barrier function [47] and regulates NO production [48]. Down-regulation of SST and GJD2 might thus fragilize the RPE barrier. Finally, down-regulation of OMG in RPE cells, which encodes oligodendrocyte-myelin glycoprotein, could indicate a role for the RPE in the maintenance of choroidal nerves, which control the choroidal blood flow [49] through a secreted isoform of OMG [50].

The subset of genes that are up- or down-regulated by aldosterone and cortisol + RU486, and not by cortisol alone, mimics the effect of an imbalance toward MR overactivation in human RPE cells. One group of genes encodes proteins involved in ECM remodeling, epithelial-mesenchymal transition (EMT) and RPE cell proliferation and migration, such as ITGB3 encoding the integrin subunit beta-3, PLAUR encoding the urokinase plasminogen activator receptor (uPAR) and FOSL1 encoding the FOS like 1 AP-1 transcription factor subunit protein. Interestingly, FOSL1 controls the expression of PLAUR and ITGB3 [51]. The UPAR is expressed at the basolateral membrane of RPE cells [52], and activation of uPA-uPAR pathways favors choroidal neovascularization [53] and induces RPE EMT and proliferation [54]. In addition, the UPAR has been shown to interact with the integrin subunit beta-3 expressed on RPE cells $[55,56]$, inducing extracellular proteolysis by en- 
hancing cell surface plasminogen activation. Three other down-regulated genes (CNN1, $M G P$ and $A M T N$ ) encode proteins involved in the rigidity of the ECM. MGP encodes the matrix glia protein, a calcium-binding ECM protein with the strongest inhibitory effect on vascular calcification. It is expressed in the trabecular meshwork and the anterior sclera, the suprachoroidal space and around the optic nerve [57]. Deficiency in MGP induces vascular calcification and cerebral arteriovenous malformations [58]. Down-regulation of MGP could favor calcification and rigidity of choroidal vessels.

TNFSF18 and PTX3, up-regulated by MR activation, encode proteins involved in immune and inflammatory balance. TNFSF18, encoding the glucocorticoid-induced TNFrelated ligand 3 (GITR3) in RPE cells [59], abrogates RPE-mediated immunosuppression of $\mathrm{CD}^{+} \mathrm{T}$-cells which is considered as a possible mechanism for ocular immune privilege [60]. Its overexpression could thus alter the subretinal immune suppression. On the other hand, pentraxin 3 (PTX3) overexpression binds factor $\mathrm{H}$ and prevents oxidation-mediated activation of inflammasome in RPE cells [61].

Several genes encoding proteins involved in RPE metabolism are down-regulated. $A B C C 3$, which encodes the multidrug resistance protein 3 (MRP3) in RPE cells [62], regulates the efflux of glucuronide steroids including estradiol and testosterone. And GDNF family receptor alpha 2 (encoded by GFRA2) could be involved in decreased photoreceptor (OS) phagocytosis [63].

Altogether, these results indicate that MR overactivation in RPE cells by endogenous ligands could favor pathogenic features. This hypothesis was further explored in mice overexpressing the human MR. At 9 months, P1.hMR mice showed choroidal vasodilation, as observed previously in rodents treated with acute aldosterone ocular injection [14], and elongation of photoreceptors OS, reflecting a decrease in RPE phagocytosis, focal alteration of the RPE/choroid interface and migration of RPE cells. In addition, albumin staining showed an increase in transport in the RPE cells and possible leakage through the RPE barriers, reflecting alteration of the RPE barrier. Interestingly, no major change was observed in the neural retina of these mice. The retinal phenotype of P1.hMR mice mimics human pachychoroid pigment epitheliopathy [64]. Interestingly, numbers of genes and pathways, identified in the iRPE cell model were also regulated in the rat RPE/choroid complex by acute aldosterone injections [21].

In conclusion, this study shows that the RPE is a corticosteroid-sensitive epithelium and that specific MR pathway overactivation by endogenous corticoids regulates genes involved in RPE phagocytosis of OS, inflammation and immunity, barrier function, ECM remodeling, ion transports and EMT transition. The P1.hMR transgenic mouse model confirmed the pathogenic role of MR overactivation in the retina and its possible link with the pachychoroid-disease spectrum. Further studies should confirm these findings and molecular targets on other RPE cell lines.

\section{Material and Methods}

\subsection{Human iPSC Differentiation into RPE Cells}

Human iPSCs obtained from a healthy donor (Dr. David M. Gamm, Department of Ophthalmology and Visual Sciences, University of Wisconsin-Madison, United States) were expanded and differentiated into iRPE as described previously [26] (Figure 1a). TER values were measured weekly with an epithelial voltohmmeter device (EVOM2, World Precision Instruments, Friedberg, Germany) using standard chopstick fixed double electrodes.

\subsection{Corticosteroid Treatments of iRPE Cultured Cells}

Cells were seeded at P3 in cell culture plastic dishes or transwell filters. On day 35, one week prior to corticosteroid treatments, RDMw/oA medium was removed and iRPE cells were incubated in experimental corticosteroid-free medium (DMEM, high glucose, HEPES, no phenol red (Thermo Fisher Scientific, Saint Aubin, France)); 10\% fetal bovine serum, charcoal stripped (Thermo Fisher Scientific). On day 42, depending on the experiment, iRPE cells were treated for $1 \mathrm{~h}$ or $24 \mathrm{~h}$ with the following corticosteroids treatments: aldosterone 
$\left(10^{-9} \mathrm{M}, 10^{-8} \mathrm{M}, 10^{-7} \mathrm{M}\right.$ or $\left.10^{-6} \mathrm{M}\right)$, aldosterone $\left(10^{-7} \mathrm{M}\right)$ plus spironolactone $\left(10^{-5} \mathrm{M}\right)$, aldosterone $\left(10^{-7} \mathrm{M}\right)$ plus RU-486 $\left(10^{-5} \mathrm{M}\right)$, cortisol $\left(10^{-9} \mathrm{M}, 10^{-8} \mathrm{M}, 10^{-7} \mathrm{M}\right.$ or $\left.10^{-6} \mathrm{M}\right)$, cortisol $\left(10^{-7} \mathrm{M}\right)$ plus spironolactone $\left(10^{-5} \mathrm{M}\right)$, cortisol $\left(10^{-7} \mathrm{M}\right)$ plus RU-486 $\left(10^{-5} \mathrm{M}\right)$. As corticosteroids were dissolved in ethanol $(\mathrm{EtOH})$ or methanol $(\mathrm{MeOH})$, control cells were treated with $0.1 \% \mathrm{EtOH}$ or $\mathrm{MeOH}$ in medium.

\subsection{Qualitative RT-PCR and RT-qPCR}

Total RNA was isolated from iRPE cells using the RNeasy Mini Kit (QIAGEN, Hombrechitikon, Switzerland). For qualitative analysis, PCR was performed on cDNA samples with the KAPA Taq PCR Kit (Merck, Schaffhausen, Switzerland) and PCR products were visualized on $2 \%$ agarose gels. RT-qPCR using a LightCycler ${ }^{\circledR} 96$ (Roche Applied Science, Basel, Switzerland) and SYBR ${ }^{\circledR}$ Green detection method. The following equation, which is a function of PCR efficiency and quantification cycles of both the target and the reference gene, was used for final ratio calculation. Ratio $=\mathrm{E}_{\mathrm{R}} \mathrm{CqR}^{\mathrm{C}} \mathrm{E}_{\mathrm{T}} \mathrm{CqT}^{\mathrm{T}}$, where $\mathrm{E}_{\mathrm{R}}, \mathrm{Cq}_{\mathrm{R}}, \mathrm{E}_{\mathrm{T}}$ and $\mathrm{Cq}_{\mathrm{T}}$ are the amplification efficiency of the reference gene, the quantification cycle of the reference gene, the amplification efficiency of the target gene and the quantification cycle of the target gene, respectively. Standard curve was set up with five dilution steps and mixed cDNA pooled from all condition samples in order to determine the amplification efficiency of target and reference genes. The PCR efficiency was calculated using the formula $\mathrm{E}=10^{-1 / \text { slope }}$. All primers' amplification efficiencies ranged between 1.90 and 2.10. Housekeeping genes GAPDH (human cDNA samples), $\beta$-Actin (mouse cDNA samples) and Rpl8 (rat cDNA samples) served as reference genes for normalization. Relative mRNA expression values for each gene of interest were set as 1 in the control and were represented as fold changes in experimental conditions. Gene-specific primers used for qualitative RT-PCR and RT-qPCR analysis are listed in Supplementary Table S20.

\subsection{RNA Sequencing}

Total RNA samples extracted from iRPE were sequenced at the iGenSeq transcriptomic platform of the Brain and Spine Institute (ICM, Paris, France). RNA quality was checked by capillary electrophoresis (Agilent 2100 Bioanalyzer system, Les Ulis, France), and RNA with integrity numbers (RIN) ranging from 7.8 to 8.2 was accepted for library generation. Quality of raw data was evaluated with FastQC. Libraries were prepared with Roche KAPA mRNA HyperPrep kit and sequenced with the Illumina NextSeq 500 Sequencing system using NextSeq 500 High Output Kit v2 (150 cycles), 400 million of reads, 50Gbases. STAR v2.5.3a was used to align reads on reference genome hg19 using standard options. Quantification of gene and isoform abundances was performed with RSEM 1.2.28, prior to normalization on library size with edgeR bioconductor package. Finally, differential analysis was also conducted with edgeR. Multiple hypothesis adjusted $p$-values were calculated with the Benjamini-Hochberg procedure to control FDR.

\subsection{Western Blot Analysis}

For the analysis of endogenous MR and GR protein expression in the cytoplasmic and nuclear fractions, iRPE cells were seeded at P3 on Matrigel-coated 6-well cell culture plates and grown for 42 days. Following aldosterone or cortisol $\left(10^{-6} \mathrm{M}\right) 1 \mathrm{~h}$ treatment, cells were placed on ice and washed twice with cold PBS. Total cytoplasmic and nuclear proteins were extracted using the NE-PER Nuclear and Cytoplasmic Extraction Reagents (Thermo Fisher Scientific) according to the manufacturer's instructions. For PTGER2 and S100A2 endogenous protein expression analysis, iRPE cells were plated and grown at P3 in Matrigel-coated transwell cell culture inserts (Merck) for 42 days. Following experimental $24 \mathrm{~h}$ treatments, the RIPA lysis and extraction buffer (Tris HCL at pH 8 (50 mM); NaCl (150 mM); $1 \%$ NP-40; $0.5 \%$ sodium deoxycholate; $0.1 \%$ sodium dodecyl sulfate (SDS)), complemented with protease (Merck) and phosphatase (Merck) inhibitor cocktails, was used to recover total proteins. Samples were homogenized, centrifuged at $14^{\prime} 000 \mathrm{rpm}$ for 30 min at $4{ }^{\circ} \mathrm{C}$, and supernatants were collected. Protein concentration was measured 
(Pierce BCA Protein Assay Kit, Thermo Fisher Scientific) before dilution and denaturation. Protein samples (30-40 $\mu \mathrm{g})$, along with a molecular weight marker were separated by SDSPAGE and then transferred onto a nitrocellulose or a PVDF membrane (BIO-RAD, Cressier, Switzerland). Membranes were blocked $1 \mathrm{~h}$ at room temperature (RT) in $1 \mathrm{X}$ blocking buffer (Tris base $(20 \mathrm{mM}) ; \mathrm{NaCl}(137 \mathrm{mM})$; Milli-Q $\mathrm{H}_{2} \mathrm{O} ; \mathrm{pH}$ 7.6; 0.1\% Tween $20 ; 1-5 \%$ nonfat dry milk or $2 \%$ bovine serum albumin). Blots were incubated with primary antibodies overnight at $4{ }^{\circ} \mathrm{C}$, washed three times for $5 \mathrm{~min}$, incubated for $1 \mathrm{~h}$ at RT with secondary HRP-conjugated antibodies and washed again three times for $5 \mathrm{~min}$ before being developed using chemiluminescent HRP substrate detection kits (Advansta, Luzern, Switzerland). Bands were revealed (Azure Biosystems, Baden, Switzerland) and quantified using the ImageJ software (National Institutes of Health, University of Wisconsin, WI, USA). List of primary and secondary antibodies and dilutions used for Western blot analysis is available in Supplementary Table S21).

\subsection{Immunocytochemistry on iRPE Cells}

iRPE cells were cultured on coverslips or $12 \mathrm{~mm}$ diameter transwells (Sigma-Aldrich, Schaffhausen, Switzerland) and coated with MRF (at a 1:30 dilution) in RDMsA for 42 days before processing for immunostaining. Briefly, cells were fixed in $4 \%$ paraformaldehyde for 10-20 min at RT, rinsed with PBS and blocked for 3-5 h in 5\% fetal bovine serum $+5 \%$ normal goat serum $+0.1 \%$ Triton X-100 in PBS 1X. Primary antibodies (Supplementary Table S21) were incubated overnight at $4{ }^{\circ} \mathrm{C}$ in blocking solution. Primary antibodies were washed with PBS before secondary antibody (Supplementary Table S21) incubation for $1 \mathrm{~h}$ at RT in PBS. After washing steps with PBS, transwell membranes were cut and mounted in Mowiol. Z-stacks were acquired using a LSM700 confocal microscope (Zeiss, Feldbach, Switzerland). For immunocytochemistry on cell sections, after cell fixation, transwell membranes were embedded on OCT compound and $7 \mu \mathrm{m}$ sections were performed. Immunostainings were performed as described above. Images were acquired with a BX60 microscope from Olympus equipped with a DP72 camera or a Leica DM6B microscope equipped with a DFC9000GT camera and with confocal microscope.

\subsection{Corticosteroid Profiling in Human Ocular and Cell Culture Media}

The profile of corticosteroid hormones was established using a highly sensitive and specific liquid chromatographic method coupled with tandem mass spectrometric detection (LC-MS/MS) that allows simultaneous quantification of steroids, targeting the mineralocorticoid (progesterone,11-deoxycorticosterone, corticosterone, 18-hydroxycorticosterone and aldosterone) and the glucocorticoid (17-hydroxyprogesterone, 11-deoxycortisol, cortisol (F) and cortisone (E)) pathways as previously described (Travers, S et al. Multiplexed steroid profiling of gluco- and mineralocorticoids pathways using a liquid chromatography tandem mass spectrometry method, J Steroid BiochemMolBiol 2017). HSD enzymes interconvert the active cortisol and inactive cortisone. By determining the product-to-substrate ratio $(\mathrm{E} / \mathrm{F})$, we compared the HSD activities between different samples.

\subsection{Transgenic Mice}

P1.hMR mice, in which the transcription of hMR is directed by the proximal P1 promoter, exhibit a widespread and relatively strong transgene expression [65]. Wild-type animal littermates with normal endogenous MR expression and no human MR transgene expression were used as controls. Mice were housed in the animal facility under pathogenfree conditions and in a temperature- $\left(23 \pm 1{ }^{\circ} \mathrm{C}\right)$ and humidity-controlled $(60 \%)$ room with an automatic $12 \mathrm{~h}$ light $/ 12 \mathrm{~h}$ dark cycle. Laboratory chow and tap water were supplied ad libitum. Animal maintenance and experimental procedures were in accordance with the European Communities Council Directives 86/609/EEC and the French national regulations and approved by the local ethical committee "Comité d'éthique en experimentation animal CAPSUD" under the identification number 13837/2018022715591505 V4. 


\subsection{RT-qPCR of RPE-Choroid Complex}

RPE-choroid complexes were dissected from enucleated eyes, snap-frozen in liquid nitrogen and stored at $-80{ }^{\circ} \mathrm{C}$ until use. Total RNA was isolated using the RNeasy Mini Kit (QIAGEN). First-strand complementary DNA was synthesized using random primers (Thermo Fisher Scientific) and SuperScript II reverse transcriptase (Thermo Fisher Scientific). Transcript levels of mouse $N r 3 c 2$, human NR3C2 and mouse $N r 3 c 1$ were analyzed by quantitative PCR performed in CFX384 Touch Real-Time PCR Detection System with SYBR Green detection. $\beta$-Actin was used as housekeeping gene. Delta CT threshold calculation was used for relative quantification of results. The sequences of primers were: mouse $\mathrm{Nr} 3 \mathrm{c} 2$, forward $5^{\prime}$-ATG GAA ACC ACA CGG TGA CCT- ${ }^{\prime}$, reverse $5^{\prime}$-GCC TCA TCT CCA CAC ACC AAG-3'; human NR3C2, forward 5'-CCC TCT GAA CAT GAC ATC TTC G-3', reverse $5^{\prime}$-CTG GAG CCT CGA TTT TCA AC- $3^{\prime}$; mouse $\mathrm{N} r 3 \mathrm{c} 1$, forward $5^{\prime}$-TTC GCA GGC CGC TCA GTG TT- $3^{\prime}$, reverse $5^{\prime}$-TTG GGA GGT GGT CCC GTT GCT-3'; $\beta$-Actin, forward $5^{\prime}$-AAG TAC CCC ATT GAA CAT GGC A-3', reverse $5^{\prime}$-CAT CTT TTC ACG GTT GGC CTT A-3'.

\subsection{In Vivo Retinal Morphology}

Retinal morphology was assessed in vivo under anesthesia (ketamine $100 \mathrm{mg} / \mathrm{kg}$, xylazine $10 \mathrm{mg} / \mathrm{kg}$ ) using MICRON III image-guided optical coherence tomography (OCT, Phoenix Research Labs, Pleasanton, CA, USA). Pupils were dilated with drops of MYDRIATICUM ( $2 \mathrm{mg} / 0.4 \mathrm{~mL}$, VIDAL, Issy les Moulineaux, France). OCT scan location and direction were visualized on a bright-field retinal image, and OCT real-time images of the retinal cross sections passing through optic nerve were taken with MICRON OCT software.

\subsection{Retinal Histology}

Enucleated eyes from 9-months-old P1hMR transgenic and wild-type mice were fixed with $4 \%$ paraformaldehyde (PFA) and $0.5 \%$ glutaraldehyde for $2 \mathrm{~h}$, dehydrated in a graded alcohol series and embedded in historesin (Leica, Heidelberg, Germany). Sections of $5 \mu \mathrm{m}$ were obtained using a Leica Jung RM2055 microtome and stained with $1 \%$ toluidine blue. Retinal morphology was observed in bright field using Olympus BX51 microscope (Olympus, Rungis, France). For quantification, cross sections at the level of optic nerve head were selected. Serial photographs were taken with $40 \times$ magnification starting from the region adjacent to the optic nerve to the periphery. Measurements of area of choroid and photoreceptor segments were performed on 10 photographs/eye, 5 on each side of optic nerve using ImageJ. Photoreceptor segments were measured from the outer side of the outer nuclear layer to the apices of the RPE cells, and the choroid was measured from the outer side of the Bruch's membrane to the lamina fusca. Thickness of RPE cells was measured from the RPE villosities to the basal membrane every $200 \mu \mathrm{m}$ nasal and temporal to the optic nerve on at least 10 photographs/eye ( $n=8$ eyes per group). Average choroidal and photoreceptor segment area per photograph/eye and average RPE thickness/eye were used for comparison.

\subsection{Immunofluorescence of Albumin}

Enucleated eyes were fixed in $4 \%$ PFA for $2 \mathrm{~h}$, then snap-frozen in Tissue-Tek OCT compound (Bayer Diagnostics, Puteaux, France). Cryosections $(10 \mu \mathrm{m})$ were collected on slides. After permeabilization with $0.1 \%$ Triton X100, sections were incubated with FITC-coupled goat anti-mouse albumin antibody (1:100, Bethyl, Montgomery, TX, USA) for $1 \mathrm{~h}$. Cell nuclei were counter-stained with 4',6-Diamidino-2-Phenyl-Indole (DAPI, 1:5000, Sigma-Aldrich, Saint Quentin Fallavier, France). Images were taken using an Olympus BX51 fluorescence microscope.

\subsection{Statistics}

Quantitative data were expressed as mean \pm SEM. Statistical analysis was conducted using the GraphPad Prism 5 program (GraphPad Software, San Diego, CA, 
USA). The unpaired $t$-test with Welch's correction was used to compare two groups. The Kruskal-Wallis and Dunn's test were used to compare more than two groups. $p<0.05$ was considered significant.

Supplementary Materials: The following are available online at https:/ / www.mdpi.com/article/10 $.3390 /$ ijms22179618/s1.

Author Contributions: J.C. performed cell experiments, analyzed results and wrote the manuscript. M.Z. performed in vivo experiments and helped with the manuscript. T.F. provided technical help with cell experiments. E.G. provided technical help with in vivo experiments. L.J. performed semithin sections and immunohistochemistry. L.K. contributed to cell experiments. J.G. contributed to bioinformatics. D.L.M., S.V. and M.L. provided the P1hMR mice. E.P. performed corticoid measurements. Y.A. helped with iRPE differentiation and the manuscript. F.B.-C. supervised the work, analyzed the results and wrote the manuscript. All authors have read and agreed to the published version of the manuscript.

Funding: This work received grants from national agencies: ANR (Agence Nationale de la Recherche) grant ROCK-SUR-MER 15 CE-18 0032; FNS (Fonds National Suisse) grant \# 32003015640.

Institutional Review Board Statement: The study was conducted according to the guidelines of the European Communities Council Directive 86/609/EEC. All animal experiments were approved by the Ethics Committee of CAPSUD under the identification number 13837/2018022715591505 V4. The collection and storage of human vitreous and aqueous humor was approved by the Ethical Committee CPP Ile de France (N²016-nov-14390).

Data Availability Statement: All data are available upon reasonable request. Raw RNA seq data will be made available on Gene Expression Omnibus GSE172478 (https:/ / www.ncbi.nlm.nih.gov / geo/query / acc.cgi?acc=GSE172478, accessed on 20 July 2021).

Acknowledgments: The authors thank Julie Perrot for her help in animal experiments.

Conflicts of Interest: The authors declare no conflict of interest.

Ethical Approval: The research conducted was given ethical approval. Animal maintenance and experimental procedures were in accordance with the European Communities Council Directives 86/609/EEC and the French national regulations and approved by the local ethical committee “Comité d'éthique en experimentation animal CAPSUD" under the identification number $13837 / 2018022715591505$ V4.

\section{References}

1. Bourne, A.R.R.; Jonas, J.B.; Bron, A.M.; Cicinelli, M.V.; Das, A.; Flaxman, S.R.; Friedman, D.; Keeffe, J.E.; Kempen, J.H.; Leasher, J.; et al. Prevalence and causes of vision loss in high-income countries and in Eastern and Central Europe in 2015: Magnitude, temporal trends and projections. Br. J. Ophthalmol. 2018, 102, 575-585. [CrossRef] [PubMed]

2. Daruich, A.; Matet, A.; Moulin, A.; Kowalczuk, L.; Nicolas, M.; Sellam, A.; Rothschild, P.-R.; Omri, S.; Gélizé, E.; Jonet, L.; et al. Mechanisms of macular edema: Beyond the surface. Prog. Retin. Eye Res. 2018, 63, 20-68. [CrossRef] [PubMed]

3. Strauss, O. The retinal pigment epithelium in visual function. Physiol. Rev. 2005, 85, 845-881. [CrossRef] [PubMed]

4. Reichhart, N.; Strauß, O. Ion channels and transporters of the retinal pigment epithelium. Exp. Eye Res. 2014, 126, 27-37. [CrossRef]

5. Miyamoto, N.; Iossifov, D.; Metge, F.; Behar-Cohen, F. Early effects of intravitreal triamcinolone on macular edema: Mechanistic implication. Ophthalmology 2006, 113, 2048-2053. [CrossRef]

6. Hadayer, A.; Schaal, S. Delivery of steroids into the eye for the treatment of macular edema. Expert Opin. Drug Deliv. 2016, 13, 1083-1091. [CrossRef] [PubMed]

7. Nicholson, B.P.; Atchison, E.; Idris, A.A.; Bakri, S.J. Central serous chorioretinopathy and glucocorticoids: An update on evidence for association. Surv. Ophthalmol. 2018, 63, 1-8. [CrossRef]

8. Guarneri, P.; Guarneri, R.; Cascio, C.; Pavasant, P.; Piccoli, F.; Papadopoulos, V. Neurosteroidogenesis in rat retinas. J. Neurochem. 2002, 63, 86-96. [CrossRef]

9. Bucolo, C.; Drago, F. Effects of neurosteroids on ischemia-reperfusion injury in the rat retina: Role of $\sigma 1$ recognition sites. Eur. J. Pharmacol. 2004, 498, 111-114. [CrossRef] [PubMed]

10. Smith, S.B.; Wang, J.; Cui, X.; Mysona, B.A.; Zhao, J.; Bollinger, K.E. Sigma 1 receptor: A novel therapeutic target in retinal disease. Prog. Retin. Eye Res. 2018, 67, 130-149. [CrossRef] [PubMed]

11. Bucolo, C.; Drago, F.; Lin, L.-R.; Reddy, V.N. Neuroactive steroids protect retinal pigment epithelium against oxidative stress. Neuroreport 2005, 16, 1203-1207. [CrossRef] [PubMed] 
12. Zmijewski, M.A.; Sharma, R.K.; Slominski, A.T. Expression of molecular equivalent of hypothalamic-pituitary-adrenal axis in adult retinal pigment epithelium. J. Endocrinol. 2007, 193, 157-169. [CrossRef] [PubMed]

13. Zhao, M.; Valamanesh, F.; Celerier, I.; Savoldelli, M.; Jonet, L.; Jeanny, J.; Jaisser, F.; Farman, N.; Behar-Cohen, F. The neuroretina is a novel mineralocorticoid target: Aldosterone up-regulates ion and water channels in Müller glial cells. FASEB J. 2010, 24, 3405-3415. [CrossRef] [PubMed]

14. Zhao, M.; Célérier, I.; Bousquet, E.; Jeanny, J.-C.; Jonet, L.; Savoldelli, M.; Offret, O.; Curan, A.; Farman, N.; Jaisser, F.; et al. Mineralocorticoid receptor is involved in rat and human ocular chorioretinopathy. J. Clin. Investig. 2012, 122, 2672-2679. [CrossRef] [PubMed]

15. Wilkinson-Berka, J.L.; Tan, G.; Jaworski, K.; Harbig, J.; Miller, A.G. Identification of a retinal aldosterone system and the protective effects of mineralocorticoid receptor antagonism on retinal vascular pathology. Circ. Res. 2009, 104, 124-133. [CrossRef] [PubMed]

16. Golestaneh, N.; Picaud, S.; Mirshahi, M. The mineralocorticoid receptor in rodent retina: Ontogeny and molecular identity. Mol. Vis. 2002, 8, 221-225. [PubMed]

17. Wilkinson-Berka, J.L.; Agrotis, A.; Deliyanti, D. The retinal renin-angiotensin system: Roles of angiotensin II and aldosterone. Peptides 2012, 36, 142-150. [CrossRef] [PubMed]

18. Wilkinson-Berka, J.L.; Behar-Cohen, F. Angiotensin II and aldosterone: Co-conspirators in ocular physiology and disease. Exp. Eye Res. 2020, 194, 108005. [CrossRef] [PubMed]

19. Daruich, A.; Matet, A.; Dirani, A.; Bousquet, E.; Zhao, M.; Farman, N.; Jaisser, F.; Behar-Cohen, F. Central serous chorioretinopathy: Recent findings and new physiopathology hypothesis. Prog. Retin. Eye Res. 2015, 48, 82-118. [CrossRef] [PubMed]

20. Allingham, M.J.; Tserentsoodol, N.; Saloupis, P.; Mettu, P.S.; Cousins, S.W. Aldosterone exposure causes increased retinal edema and severe retinopathy following laser-induced retinal vein occlusion in mice. Investig. Opthalmology Vis. Sci. 2018, 59, 3355-3365. [CrossRef] [PubMed]

21. Canonica, J.; Mehanna, C.; Bonnard, B.; Jonet, L.; Gelize, E.; Jais, J.-P.; Jaisser, F.; Zhao, M.; Behar-Cohen, F. Effect of acute and chronic aldosterone exposure on the retinal pigment epithelium-choroid complex in rodents. Exp. Eye Res. 2019, $187,107747$. [CrossRef] [PubMed]

22. Miura, Y.; Roider, J. Triamcinolone acetonide prevents oxidative stress-induced tight junction disruption of retinal pigment epithelial cells. Graefe's Arch. Clin. Exp. Ophthalmol. 2009, 247, 641-649. [CrossRef] [PubMed]

23. Tombran-Tink, J.; Lara, N.; Apricio, S.; Potluri, P.; Gee, S.; Ma, J.-X.; Chader, G.; Barnstable, C. Retinoic acid and dexamethasone regulate the expression of PEDF in retinal and endothelial cells. Exp. Eye Res. 2004, 78, 945-955. [CrossRef] [PubMed]

24. Arndt, C.; Sari, A.; Ferre, M.; Parrat, E.; Courtas, D.; De Seze, J.; Hache, J.; Matran, R. Electrophysiological effects of cortico-steroids on the retinal pigment epithelium. Invest. Ophthalmol. Vis. Sci. 2001, 42, 472-475.

25. Singh, R.; Shen, W.; Kuai, D.; Martin, J.M.; Guo, X.; Smith, M.A.; Perez, E.T.; Phillips, M.J.; Simonett, J.M.; Wallace, K.A.; et al. iPS cell modeling of best disease: Insights into the pathophysiology of an inherited macular degeneration. Hum. Mol. Genet. 2012, 22, 593-607. [CrossRef]

26. Udry, F.; Decembrini, S.; Gamm, D.M.; Déglon, N.; Kostic, C.; Arsenijevic, Y. Lentiviral mediated RPE65 gene transfer in healthy hiPSCs-derived retinal pigment epithelial cells markedly increased RPE65 mRNA, but modestly protein level. Sci. Rep. 2020, 10, 8890. [CrossRef]

27. Brandl, C. Generation of functional retinal pigment epithelium from human induced pluripotent stem cells. In Retinal Degeneration. Methods in Molecular Biology; Weber, B.H.F., Langmann, T., Eds.; Humana: New York, NY, USA, 2018; pp. 87-94. [CrossRef]

28. Faresse, N.; Vitagliano, J.; Staub, O. Differential ubiquitylation of the mineralocorticoid receptor is regulated by phosphorylation. FASEB J. 2012, 26, 4373-4382. [CrossRef] [PubMed]

29. Faresse, N.; Ruffieux-Daidie, D.; Salamin, M.; Gomez-Sanchez, C.E.; Staub, O. Mineralocorticoid receptor degradation is promoted by Hsp90 inhibition and the ubiquitin-protein ligase CHIP. Am. J. Physiol. Physiol. 2010, 299, F1462-F1472. [CrossRef] [PubMed]

30. Gaeggeler, H.-P.; Gonzalez-Rodriguez, E.; Jaeger, N.F.; Loffing-Cueni, D.; Nørregaard, R.; Loffing, J.; Horisberger, J.-D.; Rossier, B.C. Mineralocorticoid versus glucocorticoid receptor occupancy mediating aldosterone-stimulated sodium transport in a novel renal cell line. J. Am. Soc. Nephrol. 2005, 16, 878-891. [CrossRef]

31. Latouche, C.; El Moghrabi, S.; Messaoudi, S.; Cat, A.N.D.; Hernandez-Diaz, I.; de la Rosa, D.A.; Perret, C.; Andrés, N.L.; Rossignol, P.; Zannad, F.; et al. Neutrophil gelatinase-associated lipocalin is a novel mineralocorticoid target in the cardiovascular system. Hypertension 2012, 59, 966-972. [CrossRef] [PubMed]

32. Keenan, T.D.L.; Clark, S.; Unwin, R.; Ridge, L.; Day, A.J.; Bishop, P.N. Mapping the differential distribution of proteoglycan core proteins in the adult human retina, choroid, and sclera. Investig. Ophthalmol. Vis. Sci. 2012, 53, 7528-7538. [CrossRef] [PubMed]

33. Tenedieva, V.D.; Kulikovsky, V.P.; Lyamin, P.V.; Nepomnyaschi, V.P. The CSF aldosterone in brain tumors with brain edema. Brain Edema IX 1994, 60, 390-394. [CrossRef]

34. Uhr, M.; Holsboer, F.; Müller, M.B. Penetration of endogenous steroid hormones corticosterone, cortisol, aldosterone and progesterone into the brain is enhanced in mice deficient for both mdr1a and mdr1bP-glycoproteins. J. Neuroendocrinol. 2002, 14, 753-759. [CrossRef] [PubMed]

35. Crane, I.J.; Wallace, C.A.; McKillop-Smith, S.; Forrester, J.V. CXCR4 receptor expression on human retinal pigment epithe-lial cells from the blood-retina barrier leads to chemokine secretion and migration in response to stromal cell-derived factor 1 alpha. $J$. Immunol. 2000, 165, 4372-4378. [CrossRef] 
36. Sekiryu, T.; Fujiwara, T. Effect of prostaglandin E2 on cytosolic calcium ion and morphology in cultured bovine retinal pigment epithelium. Fukushima J. Med Sci. 1999, 45, 25-36. [PubMed]

37. Ershov, A.V.; Parkins, N.; Lukiw, W.J.; Bazan, N.G. Modulation of early response gene expression by prostaglandins in cultured rat retinal pigment epithelium cells. Curr. Eye Res. 2000, 21, 968-974. [CrossRef] [PubMed]

38. Capasso, M.; Bhamrah, M.K.; Henley, T.; Boyd, R.S.; Langlais, C.; Cain, K.; Dinsdale, D.; Pulford, K.; Khan, M.; Musset, B.; et al. HVCN1 modulates BCR signal strength via regulation of BCR-dependent generation of reactive oxygen species. Nat. Immunol. 2010, 11, 265-272. [CrossRef]

39. Capasso, M.; DeCoursey, T.; Dyer, M. pH regulation and beyond: Unanticipated functions for the voltage-gated proton channel, HVCN1. Trends Cell Biol. 2011, 21, 20-28. [CrossRef] [PubMed]

40. Milićević, N.; Mazzaro, N.; De Bruin, I.; Wils, E.; Brink, J.T.; Asbroek, A.T.; Mendoza, J.; Bergen, A.; Felder-Schmittbuhl, M.-P. Rev-Erb $\alpha$ and photoreceptor outer segments modulate the circadian clock in retinal pigment epithelial cells. Sci. Rep. 2019, 9, 11790. [CrossRef]

41. Salama, I.; Malone, P.; Mihaimeed, F.; Jones, J. A review of the S100 proteins in cancer. Eur. J. Surg. Oncol. EJSO 2008, 34, 357-364. [CrossRef] [PubMed]

42. Huang, G.; Zhang, J.; Qing, G.; Liu, D.; Wang, X.; Chen, Y.; Li, Y.; Guo, S. S100A2 silencing relieves epithelial-mesenchymal transition in pulmonary fibrosis by inhibiting the Wnt/ $\beta$-catenin signaling pathway. DNA Cell Biol. 2021, 40, 18-25. [CrossRef] [PubMed]

43. Deshpande, R.; Woods, T.L.; Fu, J.; Zhang, T.; Stoll, S.W.; Elder, J.T. Biochemical characterization of S100A2 in human keratinocytes: Subcellular localization, dimerization, and oxidative cross-linking. J. Investig. Dermatol. 2000, 115, 477-485. [CrossRef]

44. Takai, S.; Jin, D. Improvement of cardiovascular remodeling by chymase inhibitor. Clin. Exp. Pharmacol. Physiol. 2016, 43, 387-393. [CrossRef]

45. Krueger, B.; Schlötzer-Schrehardt, U.; Haerteis, S.; Zenkel, M.; Chankiewitz, V.E.; Amann, K.U.; Kruse, F.E.; Korbmacher, C. Four subunits $(\alpha \beta \gamma \delta)$ of the epithelial sodium channel $(\mathrm{ENaC})$ are expressed in the human eye in various locations. Investig. Ophthalmol. Vis. Sci. 2012, 53, 596-604. [CrossRef]

46. Klisovic, D.D.; O’Dorisio, M.S.; Katz, S.E.; Sall, J.W.; Balster, D.; O’Dorisio, T.M.; Craig, E.; Lubow, M. Somatostatin receptor gene expression in human ocular tissues: RT-PCR and immunohistochemical study. Investig. Ophthalmol. Vis. Sci. 2001, 42, $2193-2201$.

47. Fonollosa, A.; Valcarcel, M.; Salado, C.; Pereiro, X.; Vecino, E. Effect of somatostatin on human retinal pigment epithelial cells permeability. Exp. Eye Res. 2019, 184, 15-23. [CrossRef] [PubMed]

48. Vasilaki, A.; Papadaki, T.; Notas, G.; Kolios, G.; Mastrodimou, N.; Hoyer, D.; Tsilimbaris, M.; Kouroumalis, E.; Pallikaris, I.; Thermos, K. Effect of somatostatin on nitric oxide production in human retinal pigment epithelium cell cultures. Investig. Opthalmology Vis. Sci. 2004, 45, 1499-1506. [CrossRef]

49. Reiner, A.; Fitzgerald, M.E.; Del Mar, N.; Li, C. Neural control of choroidal blood flow. Prog. Retin. Eye Res. 2018, 64, 96-130. [CrossRef] [PubMed]

50. Boyle, L.H.; Traherne, J.A.; Plotnek, G.; Ward, R.; Trowsdale, J. Splice variation in the cytoplasmic domains of myelin oligodendrocyte glycoprotein affects its cellular localisation and transport. J. Neurochem. 2007, 102, 1853-1862. [CrossRef] [PubMed]

51. Galvagni, F.; Orlandini, M.; Oliviero, S. Role of the AP-1 transcription factor FOSL1 in endothelial cells adhesion and migration. Cell Adhes. Migr. 2013, 7, 408-411. [CrossRef]

52. Elner, S.G. Human retinal pigment epithelial lysis of extracellular matrix: Functional urokinase plasminogen activator receptor, collagenase, and elastase. Trans. Am. Ophthalmol. Soc. 2002, 100, 273-299.

53. Das, A. Inhibition of choroidal neovascularization by a peptide inhibitor of the urokinase plasminogen activator and receptor system in a mouse model. Arch. Ophthalmol. 2004, 122, 1844-1849. [CrossRef]

54. Sugioka, K.; Kodama, A.; Okada, K.; Iwata, M.; Yoshida, K.; Kusaka, S.; Matsumoto, C.; Kaji, H.; Shimomura, Y. TGF- $\beta 2$ promotes RPE cell invasion into a collagen gel by mediating urokinase-type plasminogen activator (uPA) expression. Exp. Eye Res. 2013, 115, 13-21. [CrossRef]

55. Anderson, D.H.; Johnson, L.V.; Hageman, G.S. Vitronectin receptor expression and distribution at the photoreceptor-retinal pigment epithelial interface. J. Comp. Neurol. 1995, 360, 1-16. [CrossRef] [PubMed]

56. Kugler, C.M.; Wei, Y.; Chapman, A.H. Urokinase receptor and integrin interactions. Curr. Pharm. Des. 2003, 9, 1565-1574. [CrossRef]

57. Borrás, T.; Smith, M.H.; Buie, L.K. A novel Mgp-Cre knock-in mouse reveals an anticalcification/antistiffness candidate gene in the trabecular meshwork and peripapillary scleral region. Investig. Ophthalmol. Vis. Sci. 2015, 56, 2203-2214. [CrossRef] [PubMed]

58. Yao, Y.; Jumabay, M.; Wang, A.; Boström, K.I. Matrix Gla protein deficiency causes arteriovenous malformations in mice. J. Clin. Investig. 2011, 121, 2993-3004. [CrossRef]

59. Kim, B.J.; Li, Z.; Fariss, R.N.; Shen, D.F.; Mahesh, S.P.; Egwuagu, C.; Yu, C.-R.; Nagineni, C.N.; Chan, C.-C.; Nussenblatt, R.B. Constitutive and cytokine-induced GITR ligand expression on human retinal pigment epithelium and photoreceptors. Investig. Ophthalmol. Vis. Sci. 2004, 45, 3170-3176. [CrossRef] [PubMed]

60. Mahesh, S.P.; Li, Z.; Liu, B.; Fariss, R.N.; Nussenblatt, R.B. Expression of GITR ligand abrogates immunosuppressive function of ocular tissue and differentially modulates inflammatory cytokines and chemokines. Eur. J. Immunol. 2006, 36, $2128-2138$. [CrossRef] 
61. Wang, L.; Cano, M.; Datta, S.; Wei, H.; Ebrahimi, K.B.; Gorashi, Y.; Garlanda, C.; Handa, J.T. Pentraxin 3 recruits complement factor $\mathrm{H}$ to protect against oxidative stress-induced complement and inflammasome overactivation. J. Pathol. 2016, 240, 495-506. [CrossRef] [PubMed]

62. Mannermaa, E.; Vellonen, K.-S.; Ryhänen, T.; Kokkonen, K.; Ranta, V.-P.; Kaarniranta, K.; Urtti, A. Efflux protein expression in human retinal pigment epithelium cell lines. Pharm. Res. 2009, 26, 1785-1791. [CrossRef]

63. Inana, G.; Murat, C.; An, W.; Yao, X.; Harris, I.R.; Cao, J. RPE phagocytic function declines in age-related macular degeneration and is rescued by human umbilical tissue derived cells. J. Transl. Med. 2018, 16, 63. [CrossRef] [PubMed]

64. Cheung, C.M.G.; Lee, W.K.; Koizumi, H.; Dansingani, K.; Lai, T.; Freund, K.B. Pachychoroid disease. Eye 2018, 33 , 14-33. [CrossRef] [PubMed]

65. Le Menuet, D.; Viengchareun, S.; Penfornis, P.; Walker, F.; Zennaro, M.C.; Lombès, M. Targeted oncogenesis reveals a dis-tinct tissue-specific utilization of alternative promoters of the human mineralocorticoid receptor gene in transgenic mice. J. Biol. Chem. 2000, 275, 7878-7886. [CrossRef] [PubMed] 